Illinois State University

ISU ReD: Research and eData

Theses and Dissertations

$2-21-2017$

\title{
Examining Different Reasons Why People Accept Or Reject Scientific Claims
}

Emilio J. C. Lobato

Illinois State University, elobato@ilstu.edu

Follow this and additional works at: https://ir.library.illinoisstate.edu/etd

Part of the Cognitive Psychology Commons

\section{Recommended Citation}

Lobato, Emilio J. C., "Examining Different Reasons Why People Accept Or Reject Scientific Claims" (2017). Theses and Dissertations. 695.

https://ir.library.illinoisstate.edu/etd/695

This Thesis is brought to you for free and open access by ISU ReD: Research and eData. It has been accepted for inclusion in Theses and Dissertations by an authorized administrator of ISU ReD: Research and eData. For more information, please contact ISUReD@ilstu.edu. 


\title{
EXAMINING DIFFERENT REASONS WHY PEOPLE ACCEPT OR REJECT SCIENTIFIC CLAIMS
}

\author{
Emilio J. C. Lobato
}

68 Pages

The current project was designed to examine how cognitive style, cultural worldview, and conspiracy ideation correspond to various levels of agreement with scientific claims. Additionally, the kinds of justifications people provide for their position on scientific issues and the kinds of possible refutations of their scientific beliefs people are able to generate were qualitatively coded and analyzed. Participants were presented with a short survey asking about their level of agreement with scientific claims about biological evolution, anthropogenic climate change, pediatric vaccines, and genetically modified foods. Participants were asked two openended questions about each topic, one prompting participants to justify their level-of-agreement rating and the other prompting participants to generate possible refutations to their belief. Participants also filled in measures of cognitive style, cultural worldview, and conspiracy ideation. I predicted that analytical thinking style would be associated with overall higher levels of agreement with scientific claims, intuitive thinking and conspiracy ideation would be associated with overall lower levels of agreement with scientific claims, and agreement with scientific claims would be a function of cultural worldview. Results showed that greater agreement with all four scientific claims is related to a greater predisposition to analytical thinking and stronger self-reported political liberalism. I further hypothesized that the frequency of distinct categories of justifications and refutations would be predicted by level of agreement 
with scientific claims. Broadly, justifications were coded as non-justifications, subjective, evidential, or deferential, and refutations were broadly coded as denials, subjective, evidential, or deferential. Results of chi-squared analysis revealed topic-specific patterns in participants' reasoning, suggesting that people do not reason about scientific topics consistently. Different scientific claims appear, instead, to be accepted or rejected for different reasons. For example, evidence may be cited for one socio-scientific issue, but subjective experience or reasoning may be used to justify others. Regression analyses indicated further the nuanced relationship between explicit reasoning provided by participants and their agreement with scientific claims. Higher agreement with all scientific claims was related to a greater frequency of explicitly referencing evidence in some form, but other categories of belief justification and belief refutation showed topic-specific relationships. Generally, findings from this research provide a crucial next step for better understanding why individuals reject established science, as well as for developing more effective means of improving scientific literacy.

KEYWORDS: Scientific Literacy, Cognitive Style, Belief Justification, Political Ideology 
EXAMINING DIFFERENT REASONS WHY PEOPLE ACCEPT OR REJECT

SCIENTIFIC CLAIMS

EMILIO J. C. LOBATO

A Thesis Submitted in Partial Fulfillment of the Requirements for the Degree of

MASTER OF SCIENCE

Department of Psychology

ILLINOIS STATE UNIVERSITY

2017 
(C) 2017 Emilio J. C. Lobato 
EXAMINING DIFFERENT REASONS WHY PEOPLE ACCEPT OR REJECT

SCIENTIFIC CLAIMS

EMILIO J. C. LOBATO

COMMITTEE MEMBERS:

Corinne Zimmerman, Chair

Eric D. Wesselmann 


\section{ACKNOWLEDGMENTS}

This research represents a body of work that I could not have completed without the help of many helpful and patient individuals. First, I would like to acknowledge the contributions of my thesis committee. Dr. Corinne Zimmerman in particular has been a driving force behind this research, and her expertise in content and method has been invaluable. Beyond that, her wisdom and friendship have also helped keep me sane throughout this process. In addition, I could not have survived graduate school without the amazing members of my cohort: Jiuyang "Joey" Bai, Kassandra Lee, Daniel Schloesser, and Tatsuya Shigeta. Their friendship, insight, and humor was and forever will be deeply appreciated. There are too many other people who have guided me, helped me, supported me, and encouraged me over the years to name, so I am forced to just generally thank everyone, friends and family, who has stayed with me as I pursued my education. In spite of all of the help I have received, any errors contained within this document are entirely my own.

E. J. C. L. 


\section{CONTENTS}

Page

ACKNOWLEDGMENTS

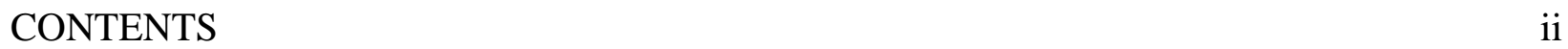

TABLES

FIGURES

CHAPTER I: INTRODUCTION 1

Demarcation Problem 2

Dual Process Models of Belief $\quad 5$

$\begin{array}{ll}\text { Justifications for Views on Scientific Topics } & 6\end{array}$

$\begin{array}{ll}\text { Cultural and Community Ideology } & 8\end{array}$

$\begin{array}{ll}\text { Conspiracy Ideation } & 12\end{array}$

Research Questions and Hypotheses $\quad 12$

$\begin{array}{ll}\text { CHAPTER II: METHOD } & 16\end{array}$

$\begin{array}{ll}\text { Participants } & 16\end{array}$

$\begin{array}{ll}\text { Materials } & 16\end{array}$

$\begin{array}{ll}\text { Procedure } & 18\end{array}$

Coding Justifications and Refutations 19

CHAPTER III: RESULTS AND DISCUSSION 22

Predictors of Agreement with Scientific Claims 23

$\begin{array}{ll}\text { Belief Justifications } & 26\end{array}$

$\begin{array}{ll}\text { Belief Refutations } & 31\end{array}$

Predictors of Justification and Refutation Types 35 
$\begin{array}{ll}\text { REFERENCES } & 45\end{array}$

APPENDIX A: SCIENTIFIC ITEMS SURVEY 52

APPENDIX B: RATIONAL-EXPERIENTIAL INVENTORY (NORRIS \& EPSTEIN, 2011) 55

APPENDIX C: CULTURAL WORLDVIEW QUESTIONNAIRE (KAHAN ET AL., 2012) 61

APPENDIX D: CONSPIRACY MENTALITY QUESTIONNAIRE (BRUDER ET AL., 2013)63

APPENDIX E: DEMOGRAPHICS QUESTIONNAIRE 64

APPENDIX F: CODING SCHEME FOR OPEN-ENDED RESPONSES 66 


\section{TABLES}

Table

Page

1. Mean Level of Agreement with the Four Scientific Claims, and Mean Scores on the Individual Difference Characteristics

2. Pearson Product Moment Correlations

3. Standardized Function and Structure Coefficients for the First Canonical Variate

4. Frequency of Belief Justification Codes for Four Science Topics

5. Comparison of Proportions of Justification Types Between Shtulman (2013) and Present Study

6. Frequency (Proportion) of Participants' Use of Each Justification Code for None, Any, or All Scientific Topics

7. Frequency of Refutation Codes for Four Scientific Topics

8. Comparison of Proportions of Refutation Types Between Shtulman (2013) and Present Study

9. Frequency (Proportion) of Participants' Use of Each Refutation Code for None, Any, or All Scientific Topics

10. Frequency of Justifications Predicted by Level of Agreement with Scientific Claims

11. Frequency of Refutations Predicted by Level of Agreement with Scientific Claims 


\section{FIGURES}

Figure $\quad$ Page

1. Coding Scheme Used in Shtulman (2013) 8 


\section{CHAPTER I: INTRODUCTION}

Improving scientific literacy is a major goal of 21 st century education (NRC, 2010, 2012), but the path to greater scientific literacy in the general public includes many challenges. Recent polls and surveys find the general public is not particularly prone to accepting scientific conclusions on major socio-political issues (Funk \& Rainie, 2015), and that for some subgroups, trust in science and acceptance of science has been decreasing over the last several decades (Gauchat, 2012). According to one line of thinking, the primary source of resistance to science stems from an information deficit in the public (Gross, 1994). If that is the case, efforts to improve the communication of science to the public should result in a greater acceptance of science by the public. The logic of this approach is intuitively appealing, but the results of programs that attempt to address this information deficit are mixed (Miller, 2001; see also Gauchat, 2012). Some topics for which there is an abundance of scientific information and consensus, such as biological evolution and anthropogenic climate change, are still hotly contested by non-scientists in the public and in politics. More information has not increased public acceptance of science.

Currently, researchers examining the public's understanding of science are moving beyond a pure deficit model approach to understanding rejection of science. Instead, many researchers are investigating the role of other individual difference variables and their relationship to accepting or rejecting science in general, or specific socio-scientific issues in particular. These variables are predominantly social or cognitive in nature, rather than educational or knowledge-based. They include cultural worldview (e.g., Kahan, 2012, 2015), political ideology and affiliation (e.g., Gauchat, 2012; Nisbet, Cooper, \& Garret, 2015; Shen \& Gromet; 2015), cognitive style (e.g., Gervais, 2015; Lindeman, 2011; Majima, 2015), and 
predisposition towards conspiracy ideation (e.g., Lewandowsky, Oberaur, \& Gignac, 2013b), each of which will be described in more detail in the following sections.

Results from these lines of inquiry have provided important contributions that afford the improvement of educational policies and science communication techniques. One limitation of these research efforts is that they are purely quantitative studies utilizing surveys comprised of true/false or Likert-scale questions. To better understand why people may accept or reject particular scientific claims, it is important to conduct qualitative research that allows individuals to elaborate on their position in addition to quantitative research to examine individual difference characteristics that relate to acceptance or rejection of science. That is the purpose of the current research. A better understanding of why people say they accept or reject science may provide new insight into how to convey scientific information to the general public.

\section{Demarcation Problem}

Before exploring the prior literature examining individual difference variables associated with acceptance or rejection of science, it is important to understand what science is.

Understanding what science is and how to distinguish it from non-science or pseudoscience is a challenging prospect. However, a person's understanding of what constitutes science may influence what topics or claims he or she considers scientific. "One's view about whether people are adept at scientific thinking depends heavily on one's view of what scientific inquiry is" (Koslowski, 1996, p. 3). The challenge associated with defining science and distinguishing science from non-science and pseudoscience is known as the demarcation problem. Interest in the demarcation problem has recently increased (Boudry, Blancke, \& Pigliucci, 2014; Still \& Dryden, 2004), perhaps in response to the current dialogues about specific scientific topics (e.g., climate change) between scholarly communities, the general public, and politicians. 
Science is frequently treated and characterized as a set of processes and methods for investigating phenomena, both by scholarly communities (e.g., scientific, philosophical) and the general public. These processes and methods vary within and between scientific disciplines depending on the epistemic obligations of the discipline (Cleland, 2001; Cleland \& Brindell, 2013; McComas, 1996). For example, theoretical aspects of disciplines such as chemistry or physics rely heavily on calculation rather than experimentation (Bauer, 1994). Previous science education standards, however, were more limited in scope with respect to teaching students about science as a method of inquiry, focusing predominantly on "the" scientific method of observation, hypothesis formation, and experimentation. This view of scientific inquiry may be why some individuals reject the consensus view on contemporary "controversial" scientific topics. The predominant evidentiary weight of some scientific topics does not bear much resemblance to "the" scientific method that was taught in primary and secondary education for generations. For example, historical field sciences, such as geology, cannot conduct experiments on hypothesized events that occurred in the past. Instead, field geologists examine the results of historical geological events, and exploit the fundamental cause-effect asymmetry to determine which hypothesized events are most probable given the collected evidence (Cleland, 2001; Cleland \& Brindell, 2013).

However, science can also be characterized as a rich and diverse set of content areas. Regardless of the processes one uses, some topics or ideas are not susceptible to true scientific investigation. For example, Bem (2011) published a series of studies that purported to find positive evidence for psi phenomena, such as precognition and premonition. The predominant responses from the skeptical scientific community tended to criticize the methodological and analytic factors of Bem's work (e.g., Rouder \& Morey, 2011). Failures to replicate Bem's results 
were used to argue that the notion of psi phenomena is, at best, problematic from a research design perspective. However, as pointed out by Schwarzkopf (2014), well-established research findings in thermodynamics about the arrow of causality mean that there is no reason to assume such phenomena (i.e., psi) could possibly exist for which testable hypotheses could be developed. Psychic abilities violate fundamental thermodynamic properties of the known universe, and accepting the premise of psychic abilities undermines the foundation of the modern understanding of causal relationships. Schwarzkopf's reasoning rests on there being boundaries of what can and cannot be considered scientific content. These boundaries are themselves usually created, maintained, or dissolved through the results of prior empirical investigation.

A similar position for demarcating science from pseudoscience was articulated by Pigliucci (2013). He suggests there are at least two broad attributes that distinguish science from pseudoscience. These attributes are breadth of internal coherence and depth of empirical knowledge. Internal coherence refers to the logical consistency among a set of propositions that gives rise to the explanatory power of a theoretical view (see for review, Thagard, 1989). The processes and contents of science could be seen as making up the depth of empirical knowledge attribute. Theoretical understanding and internal coherence ideally form a reciprocal relationship with the establishment of empirical knowledge. Coherence both extends and constrains the methods and contents of a given scientific discipline, which themselves expand and limit the scope of subsequent theoretical understanding.

Although the above review is necessarily incomplete, it provides a means to introduce and define the construct of science for the purposes of grounding the present research. Classifying something as science (or scientific) depends partly on the characteristics of both the content examined and the methods used, broadly speaking. Therefore, science is a heavily 
constrained category, requiring both a theoretically appropriate content area and associated set of rigorous methodologies that produce internally coherent explanations for natural phenomena (Pigliucci, 2013; Shtulman, 2013). This conceptualization of science can be useful in examining why some people accept scientific claims while others reject them. Acceptance or rejection of scientific claims may depend on the methodologies associated with investigating that topic, the content under investigation, or based on some other reasons unrelated to the demarcation problem. For the current study, analyzing the reasons people provide for their belief in scientific topics such as evolution, climate change, genetically-modified organisms (GMO), and pediatric vaccinations provide a window into what characteristics of scientific issues are salient to individuals who accept or reject scientific views on these issues.

\section{Dual Process Models of Belief}

Cognitive science research on belief has been aided by the recent incorporation of dualprocess models of cognition. Dual-process models posit that information processing can occur in two distinct ways (Evans, 2008; Kahneman, 2011). One mode of processing is typically automatic, rapid, and based on heuristics. This is frequently termed System 1 or Type 1 processing. The other mode of processing, System 2 or Type 2 processing, is described as a more reflective, analytical, and slower way to process information. However, these characteristics are not always present when engaging in Type 1 or Type 2 processing. Instead, these features are thought to just frequently co-occur with a more narrow and specific defining characteristic of Type 1 and Type 2 processing: Type 1 processing is characteristically autonomous whereas Type 2 processing is uniquely capable of cognitively decoupling mental representations after inhibiting autonomous Type 1 processing (Stanovich \& Toplak, 2012). 
A dual-process framework has been utilized in multiple distinct lines of research investigating scientific and paranormal beliefs (Bouvet \& Bonnefon, 2015; Gervais, 2015; Lindeman, 2011; Lindeman \& Aarnio, 2007; Lobato et al., 2014; Lobato \& Zimmerman, 2015; Majima, 2015; Pennycook, Cheyne, Seli, Koehler, \& Fugelsang, 2012). Taken together, findings from these studies suggest that a greater predisposition towards engaging in the analytical Type 2 processing is correlated with less endorsement of scientifically inaccurate or epistemically unwarranted beliefs. In contrast, a greater predisposition towards engaging in the intuitive Type 1 processing is correlated with a higher rate of belief in less scientifically or philosophically coherent phenomena. This research implies that people's beliefs about scientific topics may be influenced by their predisposition towards Type 1 or Type 2 information processing.

\section{Justifications for Views on Scientific Topics}

The importance of understanding why people accept or reject scientific claims is illustrated in the diverse research efforts to examine variables that may affect an individual's belief system. Equally relevant is research examining how people justify their belief system about scientific issues.

Recent research indicates that college students' justifications for their beliefs in scientific and paranormal phenomena are not qualitatively distinct (Shtulman, 2013). In this research, 140 student participants were asked about their beliefs in six scientific phenomena (e.g., electrons, evolution, genes) and 12 paranormal entities (e.g., angels, ghosts, karma). Participants responded to five prompts, investigating whether they believed in the existence of these phenomena, how confident they were, how many other Americans they thought held the same belief, why they hold the belief that they do (i.e., belief justifications), and what evidence might persuade them to change their mind (i.e., belief refutations). Open-ended responses to the questions probing belief 
justifications and belief refutations were coded along a hierarchical decision tree (see Figure 1). This coding scheme began with differentiating responses that actually answered the questions from responses that either clarified the respondent's position (for the belief justification prompt) or denied any possibility for evidence to change the respondent's position (for the belief refutation prompt). From there, justification responses were further sorted into those that referenced internal, subjective rationales and those that referenced external, objective rationales. External, objective rationales were further deconstructed into responses that mentioned evidential justifications - such as empirically observable properties or testable causal effects and responses that mentioned deferential justifications - such as appeals to authority or personal worldview cohesion. Analysis of the sample's belief justifications and belief refutations revealed similarity between beliefs in scientific phenomena and paranormal entities. Both sets of beliefs were predominantly justified by deferential justifications and for both sets of beliefs the majority of participants denied the possibility of their belief being refuted. Even though the methodology of the study prompted students to think in terms of evidence, most did not provide evidential reasons. These results support the idea that many college students may not perceive scientific beliefs as having a qualitatively distinct, more rigorous set of epistemological commitments than non-scientific beliefs such as paranormal beliefs.

For both scientific and non-scientific beliefs, many people do not appear to conceptualize their belief as two distinct representations of the theory and any corroborating evidence, instead combining theory and corroborating evidence in a single representation. That is, "evidence serves merely to illustrate what one knows to be true, with evidence-based and theory-based justifications functioning as interchangeable supports for a claim" (Kuhn, 1999, p. 21). As such, people may re-state a belief as its own justification. If a single representation is used for both 
belief and justification for the belief, people may struggle to come up with reasons for why they hold the beliefs they do and instead resort to circular reasoning.

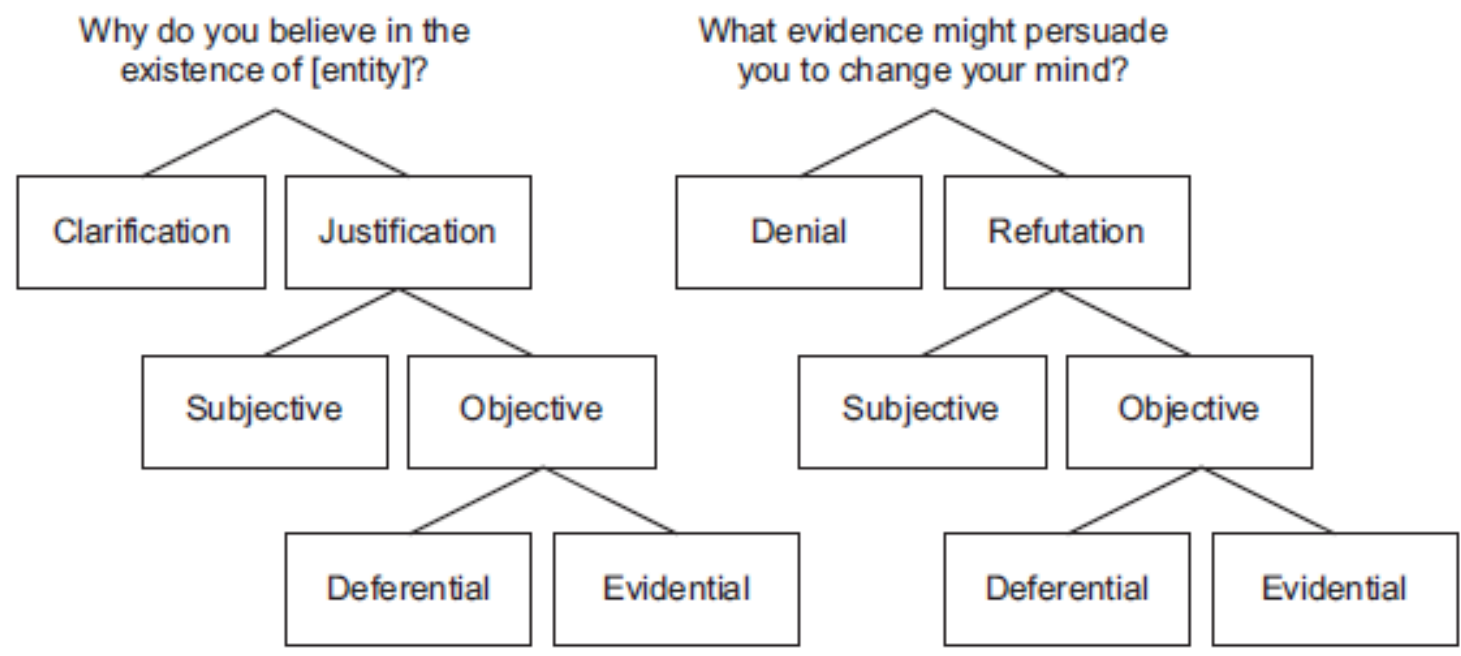

Figure 1. Coding scheme used in Shtulman (2013). From "Epistemic similarities between students' scientific and supernatural beliefs," by A. Shtulman, 2013, Journal of Educational Psychology, 105, p. 203. Copyright 2013 by American Psychological Association. Reprinted with permission.

\section{Cultural and Community Ideology}

The framing of scientific issues also matters for understanding why people adhere to the beliefs they do regarding science. Framing affects how a topic is received (Levin, Schneider, \& Gaeth, 1998). For example, Barnes and Church (2013) examined the frequency of the terms proof, evidence, establish, experiment, test, and trial in documents arguing in favor of creationism/Intelligent Design (ID) or evolution. Their analyses revealed that proponents of 
creationism/ID were approximately three times more likely than proponents of evolution to utilize cognates of proof (e.g., proved, proven) in their arguments. Authors arguing for creationism/ID were also approximately three times more likely to frame the issue of evolution in absolute terms, expressing certainty that questions regarding evolution and the origin of life could be proven (and that the proof is entirely in favor of creationist/ID arguments). The researchers argued that such a finding indicates there may be ideological group differences in the epistemological commitments of science between proponents of creationism/ID and proponents of evolutionary theory. As such, the reasons that individuals provide for believing what they do about specific scientific issues may help reveal how they generally understand science. This research also suggests that people who reject science may be more likely to frame their position in terms of certainty or provability, in contrast to the probabilistic nature of appropriate scientific inquiry.

Similarly, research also indicates that how scientific issues are framed affects how much individuals affiliated with different political parties support an issue. Shen and Gromet (2015) investigated how advances in neuroscience that influence legal and public policy (i.e., "neurolaw") are received by the general public. In a preliminary study examining the public's current understanding of how neuroscience impacts the law, the researchers found that most participants mentioned aspects of criminal trials such as lie detection or assessments of a defendant's sanity. In a subsequent study with a nationally representative sample of 1,010 participants, the researchers manipulated whether the question about acceptance of neuroscience in the legal system was framed in support of prosecutors or defendants. The researchers found that although the general public is predominantly neutral to the topic of neurolaw, how the issue is framed reveals partisan differences in acceptance. In particular, individuals affiliated with the 
Republican Party were less supportive of neurolaw when the issue was framed as benefitting the legal defense side of trials. In contrast, individuals affiliated with the Democratic Party were unaffected by how neurolaw was framed.

Whereas Shen and Gromet (2015) found the public largely neutral on the topic of neurolaw, perhaps due to the perceived complicated nature of neuroscience advances, similar partisan divides in accepting science are found for topics that have seeped into cultural and political discourse, including evolution, climate change, hydraulic fracturing (fracking), and nuclear power (Nisbet et al., 2015). When presented with ideologically dissonant scientific communications, more people engage in motivated cognition, regardless of their political ideology or orientation, compared to individuals presented with science communications that were ideologically neutral or favorable. Here, motivated cognition refers to the phenomenon by which individuals selectively interpret information provided to them in ways that are congruent with their prior beliefs or values (Kunda, 1990). That motivated cognition occurs for political liberals as well as political conservatives suggests that the role of ideology in resistance to science may depend on the specific topic being considered rather than a generalized resistance to science. Similar results of content-specific partisan differences are found in studies investigating the degree to which individuals value deference to scientific expertise in policy formation (Blank \& Shaw, 2015).

Further, the role of ideology and community identity may be more important to one's position on a scientific issue than one's content-relevant knowledge. For example, historically, distrust in science within the United States between political groups - Democrat, Republican, independent - varies as a function of which political party wins presidential elections (Gauchat, 2012). Trust in science by Democrats and Independents has remained stable since the mid-1970s, 
whereas for Republicans trust in science falls sharply with the election of conservative Republican presidents. Rejection of science and endorsement of pseudoscience is also predicted by religious affiliation, with religious participants showing a higher level of rejection of science and acceptance of pseudoscience than non-religious participants (Lobato et al., 2014). Kahan $(2012,2015)$ has argued that discussions of certain scientific topics, such as climate change, are tightly associated with one's cultural identity, including religious or political affiliation. This association between a particular opinion or belief about the issue of climate change and one's cultural identity has complicated the transmission of relevant scientific data, as well as the measurement of the public's understanding of scientific topics, because it results in individuals engaging in a form of motivated cognition that Kahan (2015; Kahan, Hoffman, Braman, Evans, \& Rachlinski, 2012) refers to as cultural cognition. Cultural cognition manifests itself in individuals' attempts to establish congruence between the commitments of groups they belong to and the perception of related facts. Group identity is more personally salient, resulting in the perception of related facts in a manner that fits with the identity.

Kahan and colleagues (Kahan \& Braman, 2006; Kahan et al., 2012) argue that cultural cognition is a combination of two orthogonal dimensions: individualism-communitarianism and hierarchy-egalitarianism. A high individualistic worldview promotes the expectation that people should be free to regulate themselves in the pursuits of their own needs. A high communitarian worldview promotes the needs of the community as superseding the needs of individuals, the goal of which is to develop a society that affords opportunities for individual success. A high hierarchical worldview seeks to protect traditional authority and role stratification. A high egalitarian worldview denies the value of role stratification, seeing it as inherently risking society falling victim to the actions of private industry and to the traditional prejudices of authority. 
Where individuals align on these two dimensions influences how information is filtered and interpreted, resulting in occasions where two people of opposing cultural worldviews can view the same information yet come to wildly incongruent, potentially antagonistic, conclusions. Thus, it would be unsurprising if people provide justifications for their scientific beliefs by referencing either a culture or community they belong to or a culture or community whose values they oppose.

\section{Conspiracy Ideation}

Research has found that the degree to which individuals accept science is negatively associated with acceptance of conspiracy theories (Lewandowsky, Gignac, \& Oberaur, 2013a; Lewandowsky et al., 2013b; Lobato et al., 2014; Lobato \& Zimmerman, 2015). Conspiracy ideation is generally regarded as a self-sustaining worldview comprised of alternative explanations for large-scale events endorsed by individuals who harbor a general distrust in

recognized authorities, particularly governments (Goertzel, 1994; Wood, Douglas, Sutton, 2011). It is not surprising, then, that conspiracy theorists also tend to reject the conclusions of mainstream scientific authorities (e.g., pharmaceutical companies, the Food and Drug Administration, the Environmental Protection Agency) on issues ranging from climate change to vaccination safety. The association between conspiracy ideation and rejection of science suggests that individuals prompted to justify their beliefs on specific scientific issues may allude to the possibility of conspiracies.

\section{Research Questions and Hypotheses}

The above broad overview of the nature of science, dual-process models of cognition, belief justifications, cultural worldview and ideology, and conspiracy ideation provide a necessary grounding for the present research. Qualitative measures will be analyzed in 
conjunction with quantitative measures to explore the relationship between select individual difference variables found relevant to scientific literacy, level of agreement with scientific claims, and justifications provided for those beliefs about scientific claims.

The first research question this research aims to answer is: Which individual difference characteristics predict acceptance or rejection of scientific claims? Based on the literature reviewed above, I hypothesized that cognitive style, cultural worldview (including political ideology and religiosity), and predisposition to conspiracy ideation would influence individuals' level of agreement with scientific claims about evolution, climate change, GMO safety, and vaccine safety. Specifically, I hypothesized that:

(H1a) A greater predisposition towards an analytical, Type 2 cognitive style would predict a higher level of agreement with scientific claims.

$\left(\mathrm{H} 1_{\mathrm{b}}\right)$ A greater predisposition towards an intuitive, Type 1 cognitive style would predict a lower level of agreement with scientific claims.

$\left(\mathrm{H} 1_{\mathrm{c}}\right)$ A greater predisposition to conspiracy ideation would predict a lower level of agreement with scientific claims.

$\left(\mathrm{H} 1_{\mathrm{d}}\right)$ Stronger political conservatism would predict a lower level of agreement with scientific claims about evolution and climate change relative to level of agreement with scientific claims about vaccine and GMO safety.

$\left(\mathrm{H} 1_{\mathrm{e}}\right)$ Stronger political liberalism would predict a lower level of agreement with scientific claims about vaccine and GMO safety relative to level of agreement with scientific claims about evolution and climate change.

$\left(\mathrm{H} 1_{\mathrm{f}}\right)$ More frequent attendance of religious services would predict a lower level of agreement with scientific claims about evolution. 
The second research question: What reasons do people provide when asked to justify their acceptance or rejection of scientific claims? Put another way, when considering the various categories of reasons an individual may have for believing as he or she does (e.g., cultural identity, perceptions of the nature of science, evidence), how do individuals differ as a function of their level of agreement with scientific claims? Shtulman's (2013) research suggests that justifications provided for scientific and paranormal beliefs are qualitatively similar. However, his research examined only college undergraduates and did not have a sufficient number of participants who rejected scientific claims, making a comparison between those who accept scientific claims and those who reject scientific claims difficult. Likewise, participants in his study were asked about the existence or non-existence of both scientific and paranormal phenomena, whereas in the current research I examine participant responses to scientific conclusions.

My hypothesis was, broadly, that there would be significant differences in the proportion of scientifically and philosophically acceptable justifications that participants provide. Specifically, I hypothesized:

$\left(\mathrm{H} 2_{\mathrm{a}}\right)$ There would be fewer scientifically or philosophically acceptable justifications compared to justifications that are not scientifically or philosophically acceptable across all topics and levels of agreement with scientific claims.

$\left(\mathrm{H} 2_{\mathrm{b}}\right)$ Higher levels of agreement with scientific claims would predict more frequent scientifically or philosophically acceptable justifications.

$\left(\mathrm{H} 2_{\mathrm{c}}\right)$ Participants' justifications would be predicted by their cultural worldview along the individualistic-egalitarianism and hierarchical-communitarian dimensions. 
The third research question the current research was designed to answer is: Do individuals who accept scientific claims differ from individuals who reject scientific claims in their ability to consider challenges to their belief? Embedded in this research question is the possibility that some individuals may be unable or unwilling to consider that sufficient evidence could be presented to challenge their position on a subject. As such, there are two general hypotheses to consider. One concerns the possibility that participants will not be able to generate refutations or challenges to their position on scientific issues:

(H3) The most common response to the belief refutation questions would be that there is no reason the participant can think of to challenge his or her position on the issue.

The final hypothesis concerns individuals who are able to generate reasons that challenge their level of agreement with the scientific claims. For these individuals, I hypothesized that there would be significant differences in the proportion of scientifically and philosophically acceptable justifications that participants provide. Specifically, I hypothesized that:

$(\mathrm{H} 4 \mathrm{a})$ There would be fewer references to scientifically or philosophically acceptable refutations compared to refutations that are not scientifically or philosophically acceptable across all topics and level of agreement with scientific claims.

$\left(\mathrm{H} 4_{b}\right)$ Higher levels of agreement with scientific claims would predict more frequent references to scientifically or philosophically acceptable refutations.

$\left(\mathrm{H} 4_{c}\right)$ Participants' refutations would be predicted by their worldview along the individualistic-egalitarianism and hierarchical-communitarian dimensions. 


\section{CHAPTER II: METHOD}

\section{Participants}

The original sample included 305 participants. After excluding participants who failed attention checks, and multiple data sets that originated from the same IP address, the final sample consisted of 244 participants with data that could be subjected to quantitative analysis and 239 participants with data that could be subjected to qualitative analysis.

Participants were recruited from the Illinois State University Psychology Department SONA Systems participant pool $(N=157)$, and the Illinois State University Computer Infrastructure and Support Services (CISS) system $(N=87)$. Participants recruited via SONA systems were compensated via course credit. Participants recruited via CISS were directed to a separate survey where they could enter their e-mail address to be entered into a raffle for a $\$ 25$ Amazon.com gift card.

A preliminary power analysis using G*Power 3.1 (Faul, Erdfelder, Lang, \& Buchner, 2007) with effect sizes from previous research (Lobato et al., 2014; Lobato \& Zimmerman, 2015) calculated a minimum sample size of 138 participants for a predicted effect size $f^{2}=.15, \alpha$ $=.05$, and power $(1-\beta)=.95$.

\section{Materials}

A survey was designed using the Qualtrics online survey software (http://www.qualtrics.com). The survey included a brief description of four scientific claims, and participants were asked to report their level of agreement with each using a six-point rating scale. Following that, participants were asked two open-ended questions designed to assess their justifications for their position and what they think about the possibility of disconfirming evidence for their position (see Appendix A). 
The four topic areas for this research are: (1) biological evolution; (2) anthropogenic climate change; (3) genetically modified foods; and (4) vaccine efficacy. Each topic was selected for its prominence in contemporary discussions about the general public's level of scientific literacy within scholarly disciplines, political discourse, and popular culture at large. Due to the prevalence of these topics in both political and popular discourse compared to other scientific topics, there exists a large disconnect between how the general public feels about these issues compared to how the relevant scientific communities feel about them. For example, although $88 \%$ of scientists from the American Association for the Advancement of Science agree that genetically modified foods are safe to eat, only $37 \%$ of adults in the United States agree with that conclusion (Funk \& Rainie, 2015). Additionally, these topics were selected because of the stereotypical media portrayal of two topics, evolution and climate change, as being resisted more by political conservatives whereas the other two topics, GMO and vaccine safety, are portrayed as more likely to be resisted by political liberals.

The Rational-Experiential Inventory (REI, see Appendix B, Norris \& Epstein, 2011) is a measure of predisposition towards Type 1 and Type 2 thinking. This version of the REI has four subscales (Rational, Imaginative, Emotional, Intuitive), but only the Rational and Intuitive subscales were analyzed for this study. Internal reliability for these subscales was found acceptable ( $\alpha=.85$ for the Rational subscale; $\alpha=.72$ for the Intuitive subscale).

The Cultural Worldview Scale (CWS, see Appendix C; Kahan et al., 2012) is a measure of cultural worldview along the dimensions of Individualism-Communitarianism and HierarchyEgalitarianism. Internal reliability for these subscales was deemed unacceptable $(\alpha=.52$ for the Individualism-Communitarianism subscale; $\alpha=.59$ for the Hierarchy-Egalitarianism subscale). 
As a result, this scale was not used in any analyses. For a full explanation of why, and possible reasons why reliability was so low, see Chapter IV: General Discussion.

The Conspiracy Mentality Questionnaire (CMQ; see Appendix D; Bruder, Haffke, Neave, Nouripanah, \& Imhoff, 2013) is a measure of predisposition towards conspiracy ideation. Internal reliability for this scale was found acceptable (Cronbach's $\alpha=.74$ ).

Lastly, a demographics questionnaire was administered asking about age, gender identity, religious affiliation, frequency of religious service attendance, political ideology, and political affiliation (see Appendix E).

\section{Procedure}

Participants were presented with a survey asking them to rate their level of agreement with four scientific claims on a 6-point Likert scale. After providing their level of agreement, participants were then asked to provide typed responses to two open-ended questions about their justification for, and possible refutations of, their position on each of the four topics. Specifically, to investigate what reasons participants use to justify their position, they were asked, "What are your reasons for your position on this topic?" To investigate what reasons, if any, participants can imagine that could challenge their position, participants were asked, "What possible reasons can you think of that would change your position on [topic]?" Participants were then asked to complete the Rational-Experiential Inventory (Norris \& Epstein, 2011), the Cultural Worldview Scale (Kahan et al., 2012), and the Conspiracy Mentality Questionnaire (Bruder, et al., 2013).

Presentation of the survey of scientific claims and the individual difference questionnaires were counterbalanced across participants. It is possible that being asked to reflect on one's reasons for their beliefs may engage metacognitive processes (Kuhn, 2000), influencing 
how participants respond to the individual difference questionnaires. Likewise, it is possible that the individual difference questionnaires may prime participants to already be thinking in terms of their intuitions, their cultural worldview, or conspiracies, influencing what kinds of justifications they may provide when prompted to. Finally, participants filled out a demographics questionnaire.

\section{Coding Justifications and Refutations}

From the 239 participants who provided responses to any of the two open-ended questions for the four topics, there was a total of 1,425 responses to the justification question (324 for the Evolution item, 344 for the Climate Change item, 395 for the GMO item, and 362 for the Vaccine item). Participants provided a total of 967 responses to the refutation question (247 for the Evolution item, 240 for the Climate Change item, 239 for the GMO item, and 241 for the Vaccine item).

A coding scheme was developed guided by the grounded theory approach to qualitative research (Corbin \& Strauss, 2014). Grounded theory is an integrated analytical approach that "allows researchers to identify relevant concepts, validate them, and explore them more fully in terms of their properties and dimensions" (p. 69). A preliminary coding scheme was developed in anticipation of participant responses based on a review of the relevant literatures on the science, history, and philosophy of science (e.g., Boudry \& Braeckman, 2011, 2012), as well as the research scientific literacy and scientific thinking (e.g., Kuhn, 2009; Munro, 2010; Zimmerman, Bisanz, \& Bisanz, 1998; Shtulman, 2013) summarized earlier, and personal communications with scholarly experts on scientific literacy (e.g., C. Zimmerman). This preliminary scheme was modified iteratively throughout the coding process (see Appendix F for the final coding scheme). 
The codes developed for the present data were also categorized into "higher-order" categories in line with the coding scheme developed by Shtulman (2013), to allow for comparisons between those findings and the present study. The coding scheme from Shtulman for belief justifications included the four following codes: Non-justifications, Subjective justifications, Evidential justifications, and Deferential justifications. From the present coding scheme, I combined several codes to fit with that coding scheme, in accordance with how Shtulman described each category. Non-justifications included the following codes: Clarifications/Qualifications, Don't Know, No Answer (empty response), and None (explicitly stated). Subjective justifications included the following codes: Logical, Moral, Religious, Cultural Identity, Experience, Belief-based/Circular, Conspiracy Ideation, Controversy, Natural, Personal Choice, Knowledge/Education, and Indifference/Don’t Care. Evidential justifications included the following codes: Empirical - Data/Evidence, Empirical - mechanism. Deferential justifications included the following codes: Authority - Scientist/Science, Authority Teacher/Class/Textbook, and Authority - Other. The coding scheme from Shtulman for belief refutations included the four following codes: Denial, Subjective refutations, Evidential refutations, and Deferential refutations. From the present coding scheme, I combined several codes to fit with that coding scheme, in accordance with how Shtulman described each category. Denial included only the following code: None (explicitly stated). Subjective refutations included the following codes: Logical, Moral, Religious, Cultural Identity, Experience, Beliefbased/Circular, Conspiracy Ideation, Controversy, Natural, Personal Choice, Knowledge/Education, Indifference/Don't Care, Counterfactual Hindsight Bias, and Answering for Others. Evidential justifications included the following codes: Empirical - Data/Evidence, Empirical - mechanism, Empirical - Unrealistic, and Empirical - Methodological. Deferential 
justifications included the following codes: Authority - Scientist/Science, Authority Teacher/Class/Textbook, and Authority - Other.

Two coders (E.L. and C.Z.) coded 100\% of the data. Initial inter-rater reliability was low $($ Cohen's $\kappa$ for Evolution items $=.61$; Climate Change items $=.67, \mathrm{GMO}$ items $=.58$; Vaccines items $=.52$. This low initial reliability was likely caused by human error due to the number of responses ( $N=1,912$ participant responses comprising 2,392 coded segments), the number of codes (21 justification codes, 25 refutation codes), and the iterative nature of the coding scheme. Some codes emerged late in the coding process and coders' revisions sometimes failed to account for the new codes (e.g., failure to remove prior, less accurate codes for an item). All disagreements were resolved by discussion.

It should be noted that the coding scheme as presently described could have been parsed apart even further. In particular, codes were agnostic to valence. For instance, a response segment could get a code for appealing to evidence by claiming evidence exists to support the scientific claim or by claiming evidence does not exist to support the scientific claim. This level of specification was unnecessary to address the hypotheses listed above, therefore coding the open-ended responses at that level of specification was not done at this time. In the same vein, the coding scheme does not acknowledge correctness or incorrectness of specific statements of fact. In addition to this being unnecessary for addressing the hypotheses, I lack sufficient expertise in each of the four scientific domains to be able to determine with high confidence if participants' response were factually correct or not. 


\section{CHAPTER III: RESULTS AND DISCUSSION}

Table 1 shows the descriptive statistics for level of agreement with the four scientific claims, and scores for each of the individual difference measures and relevant demographic information. As noted in the Materials section of Chapter II, the Cultural Worldview Scale subscales for Hierarchy-Egalitarianism and Individualism-Communitarianism failed to reach acceptable standards of internal reliability (Cronbach's $\alpha=.59$ and .52 , respectively) and was therefore excluded from analysis (thus, $\mathrm{H} 2_{\mathrm{c}}$ and $\mathrm{H} 4_{\mathrm{c}}$ were unable to be examined). Table 2 shows the Pearson Product Moment Correlations between the remaining variables (i.e., the four scientific items, the individual difference characteristics, and the demographic variables).

Table 1

Mean Level of Agreement with the Four Scientific Claims, and Mean Scores on the Individual Difference Characteristics

\begin{tabular}{llll}
\hline & Mean & SD & Range \\
\hline Conspiracy Mentality & 7.66 & 1.48 & $1-11$ \\
REI - Rational & 3.66 & 0.58 & $1-5$ \\
REI - Intuitive & 3.57 & 0.48 & $1-5$ \\
Religious Services & 2.62 & 1.44 & $1-6$ \\
Political Ideology* & 3.67 & 1.82 & $1-7$ \\
Evolution & 4.38 & 1.48 & $1-6$ \\
Climate Change & 4.37 & 1.45 & $1-6$ \\
GMO & 4.32 & 1.53 & $1-6$ \\
Vaccines & 4.33 & 1.48 & $1-6$ \\
\hline
\end{tabular}

Note. ${ }^{*}$ Forty participants were removed from this

analysis because their self-reported political ideology

was not along the liberal-conservative spectrum. 
Table 2

Pearson Product Moment Correlations

\begin{tabular}{|c|c|c|c|c|c|c|c|c|}
\hline & 2 & 3 & 4 & 5 & 6 & 7 & 8 & 9 \\
\hline 1. Evolution & 0.02 & $0.20^{*}$ & 0.07 & $-0.18 *$ & $0.23 *$ & $-0.13 *$ & -0.08 & $-0.21 *$ \\
\hline $\begin{array}{l}\text { 2. Climate } \\
\text { Change }\end{array}$ & & $-0.13 *$ & $0.13 *$ & $-0.15^{*}$ & $0.15 *$ & -0.10 & -0.05 & -0.09 \\
\hline 3. GMO & & & $0.15^{*}$ & -0.03 & $0.19 *$ & -0.08 & -0.13 & $-0.28 *$ \\
\hline 4. Vaccine & & & & -0.13 & $0.17 *$ & -0.11 & -0.07 & $-0.23 *$ \\
\hline 5. CMQ & & & & & -0.03 & $0.24 *$ & -0.06 & 0.12 \\
\hline 6. REI-R & & & & & & -0.11 & 0.05 & -0.08 \\
\hline 7. REI-I & & & & & & & -0.09 & 0.05 \\
\hline 8. Religiosity & & & & & & & & $0.31 *$ \\
\hline 9. Political & & & & & & & & \\
\hline Ideology & & & & & & & & \\
\hline
\end{tabular}

$\mathrm{GMO}=$ genetically modified organism; CMQ = Conspiracy Mentality Questionnaire;

REI-R = Rational-Experiential Inventory, Rational Subscale; REI-I = Rational-

Experiential Inventory, Intuitive Subscale

Political Ideology scored on a 1-7 Likert scale where 1 is Strongly Liberal and 7 is

Strongly Conservative

\section{Predictors of Agreement with Scientific Claims}

Canonical correlation analysis was used to assess the relationship between agreement with scientific statements and the individual difference and demographic variables. This technique allows for the analysis of the relationship between two sets of variables. In canonical analysis, synthetic variates for the set of predictor variables and the set of outcome variables are 
created and analyzed to generate "the highest correlation with the predicted value" of each set of variables (Tabachnick \& Fidell, 2007, p. 567).

The full model across functions was significant, Wilks's $\lambda=.7, F(20,641.1)=3.68, p<$ 0.001 , producing four functions with squared canonical correlations of $.28, .03, .01$, and .001 , respectively. Wilks's $\lambda$ is a measure of unexplained variance, with $1-\lambda$ representing how much variance is explained by the full model. Therefore, the full model with four functions explained $30 \%$ of the variance, although only the first function, explaining $92.51 \%$ of the explained variance (or $27.7 \%$ of total variance), was significant. All criterion variables were substantial contributors to the synthetic criterion variate, possessing standardized coefficients greater than |.40| (see Table 3). For the set of predictor variables, only the Rational subscale of the RationalExperiential Inventory and self-reported political ideology were substantial contributors to the synthetic predictor variate, possessing standardized coefficients greater than |.56|.

These results supported my hypothesis about the positive relationship between analytical thinking and agreement with scientific claims $\left(\mathrm{H} 1_{\mathrm{a}}\right)$. My hypotheses about the relationship between intuitive thinking, conspiracy ideation, and agreement with scientific claims $\left(\mathrm{H} 1_{b-c}\right)$ were not supported. The measures of intuitive thinking style and conspiracy ideation were not substantial contributors to the synthetic predictor variate, although their correlations with the synthetic predictor variate, the structure coefficient in Table 3, were sizeable and significant $(r=$ -.36 and $r=-.41$, respectively). My hypotheses regarding the relationship between agreement with scientific claims and political ideology $\left(\mathrm{H} 1_{\mathrm{d}-\mathrm{e}}\right)$ were only partially supported. Political conservatism was related to lower levels of agreement with scientific claims across all domains, whereas political liberalism was related to higher levels of agreement with each claim. My hypothesis about the relationship between religiosity and agreement with the evolution item 
Table 3

Standardized Function and Structure Coefficients for the First Canonical Variate

\begin{tabular}{lcc}
\hline Predictors & Standardized & Structure \\
\hline Conspiracy Mentality & -0.29 & $-0.41^{* *}$ \\
REI Rational & $0.57^{*}$ & $0.63^{* *}$ \\
REI Intuitive & -0.22 & $-0.36^{* *}$ \\
Religious Services & -0.17 & -0.28 \\
Political Ideology & $-0.56^{*}$ & $-0.70^{* *}$ \\
\hline Criteria & & \\
\hline Evolution & $0.51^{*}$ & $0.64 * *$ \\
Climate Change & $0.40^{*}$ & $0.40^{* *}$ \\
Genetically Modified Foods & $0.48^{*}$ & $0.59 * *$ \\
Vaccines & $0.41^{*}$ & $0.57 * *$ \\
\hline
\end{tabular}

Note. ${ }^{*}$ substantial contributors to the synthetic variate

** significantly correlated to the synthetic variate

REI $=$ Rational-Experiential Inventory

$\left(\mathrm{H} 1_{\mathrm{f}}\right)$ was unsupported. The measure of religiosity was nether a substantial contributor to the synthetic predictor variate, nor was it significantly correlated with the synthetic variate.

These results stand in contrast to stereotypical portrayals of particular scientific conclusions (e.g., climate change, evolution) being rejected by conservatives, with others (e.g., GMO safety, vaccine safety) being rejected by liberals. Participants with stronger conservative leanings simply tended to report lower agreement with politicized scientific claims than participants with stronger liberal leanings. 


\section{Belief Justifications}

Table 4 shows the frequency of belief justification codes. Across all four scientific topics, the most frequent justification was a reference to data (21.0\% of responses). Responses varied in the amount of detail participants provided when describing data. Some responses were specific, such as "All the studies related to negative side effects of vaccines have shown that they do no damage but protect from viruses" (participant 59) where the participant specifically references scientific research on alleged negative side effects of childhood vaccinations. Other participants referenced data in a more generic fashion, such as "I do believe in evolution because scientific facts make evolution easy to believe in" (participant 12), where the participant does not indicate any specific "scientific facts" that make evolution "easy to believe in." References to data were most frequently found in participant responses to the Vaccine item (37.14\% of Data codes), and least likely to occur in response to the GMO item (17.46\% of Data codes).

Following appeals to data, qualifications and clarifications were the second most common response type ( $10.1 \%$ of responses). These responses merely served to further specify the participant's response rather than justify participant's responses. An example of this type of response is, "I agree that they are largely safe but I don't know if all of them are as effective as they state they are" (participant 71). On the subject of the safety and efficacy of childhood vaccines, this participant's response clarifies agreement with safety rather than both safety and efficacy. Referencing some empirical mechanism related to the topic (e.g., Participant 90's response to the Climate Change item, "People contribute with the use of oil and coal") was the third most frequently occurring response (9.1\% of responses). Belief-based or circular responses were the fourth most common response (8.0\% of responses). These types of responses also occurred as either generic (e.g., "Because it's true", participant 2 responding to why they hold 
Table 4

Frequency of Belief Justification Codes for Four Science Topics

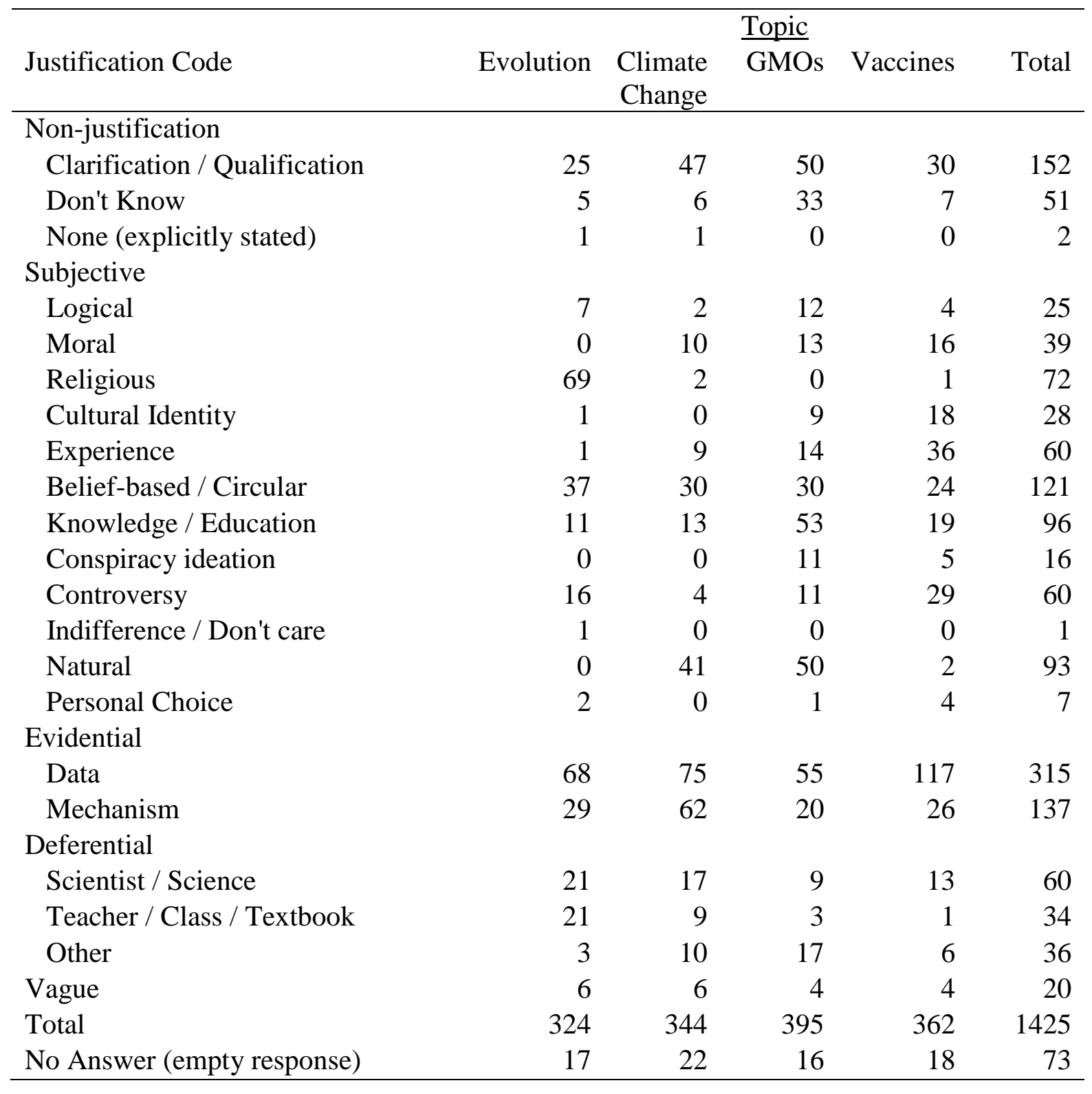


their position on the claim that childhood vaccines are safe and effective) or specific (e.g., “Genetically modified foods are safe and can be more beneficial for consumption", participant 23) responses.

A chi-squared goodness-of-fit analysis was conducted to assess the frequency of response types in comparison to the frequency of response types found in prior research (Shtulman, 2013). Because the present coding scheme was more nuanced than the coding scheme developed by Shtulman (see Figure 1), several categories in the present scheme were combined so that comparisons could be made (see Methods section in Chapter II). Results of the chi-squared test revealed that the present data significantly differed from the expected frequencies, $\chi^{2}(3,1420)=$ 6042.93, $p<.001$. As shown in Table 5, there was a higher proportion of Non-justifications and Subjective responses and a lower proportion of Deferential responses in the present study compared to Shtulman's (2013) study, whereas there was a similar proportion of Evidential responses. These results indicate that justifications that could be considered scientifically or philosophically appropriate (i.e., Evidential and Deferential) were less frequent than participant responses that were either scientifically or philosophically inappropriate (i.e., Subjective) or were not justifications. These results support my hypothesis $\left(\mathrm{H}_{2 \mathrm{a}}\right)$.

Table 6 shows the frequency and proportion of participants with justification codes across the four topics. What is revealing from these data is how infrequently participants justified their beliefs about scientific claims in a consistent manner. Even when looking only at the higherorder category level, participants were unlikely to justify their beliefs about the four topics the same way. Only 19 participants (7.9\%) referenced some evidential justification, such as empirical data or causal mechanism, in each of their responses to the four scientific claims. Thirty-one participants (13\%) referenced some subjective justification for all four topics. 
Table 5

Comparison of Proportions of Justification Types

Between Shtulman (2013) and Present Study

\begin{tabular}{lcc}
\hline Justification Type & Shtulman (2013) & Present Study \\
\hline Non-justifications & .01 & .20 \\
Subjective & .17 & .43 \\
Evidential & .29 & .28 \\
Deferential & .53 & .09 \\
\hline
\end{tabular}

Examining Tables 4 and 6 together illustrate interesting patterns of belief justification, though not all of them are surprising. For instance, $95.6 \%$ of justifications referencing religion occurred for only one topic. This is not surprising given that, of the four topics presently studied, only the topic of evolution has been framed to the general public in a manner that pits science against religion. In contrast, appeals to nature were also most likely to occur for only one topic, but were split roughly equivalently between the Climate Change and the GMO items. Responses that were coded as appeals to nature took one of two forms. One was the naturalistic fallacy, the logical fallacy implying that what is natural is better than what is artificial, illustrated in this response from participant 194 regarding GMOs, "I feel that food in its most natural state is the most nutritious." The other form appeals to nature took appeared to diminish the significance of human activity, as though humans are not able to influence nature. This idea is illustrated in the response by participant 281 regarding Climate Change: "I believe that the earth goes through periods of climate shift naturally. While humans may not be helping our enviornment [sic], I do not believe we are speeding up warming or cooling." This pattern of appealing to nature is somewhat surprising considering vaccines are artificial, and biological evolution occurs 
Table 6

Frequency (Proportion) of Participants' Use of Each Justification Code for None, Any, or All Scientific Topics

\begin{tabular}{lrrrrr}
\hline & 0 topics & 1 topic & 2 topics & 3 topics & 4 topics \\
\hline Non-justification & $82(.34)$ & $86(.36)$ & $41(.17)$ & $19(.08)$ & $11(.05)$ \\
Clarification / Qualification & $129(.54)$ & $75(.31)$ & $29(.12)$ & $5(.02)$ & $1(.00)$ \\
Don't Know & $190(.79)$ & $47(.20)$ & $2(.01)$ & $0(.00)$ & $0(.00)$ \\
No Answer (empty response) & $208(.87)$ & $10(.04)$ & $7(.03)$ & $7(.03)$ & $7(.03)$ \\
None (explicitly stated) & $238(1.00)$ & $0(.00)$ & $1(.00)$ & $0(.00)$ & $0(.00)$ \\
Subjective & $30(.13)$ & $54(.23)$ & $64(.27)$ & $60(.25)$ & $31(.13)$ \\
Logical & $215(.90)$ & $23(.10)$ & $1(.00)$ & $0(.00)$ & $0(.00)$ \\
Moral & $200(.84)$ & $39(.16)$ & $0(.00)$ & $0(.00)$ & $0(.00)$ \\
Religious & $170(.71)$ & $66(.28)$ & $3(.01)$ & $0(.00)$ & $0(.00)$ \\
Cultural Identity & $214(.90)$ & $22(.09)$ & $3(.01)$ & $0(.00)$ & $0(.00)$ \\
Experience & $189(.79)$ & $41(.17)$ & $8(.03)$ & $1(.00)$ & $0(.00)$ \\
Belief-based / Circular & $149(.62)$ & $63(.26)$ & $23(.10)$ & $4(.02)$ & $0(.00)$ \\
Knowledge / Education & $162(.68)$ & $63(.26)$ & $9(.04)$ & $5(.02)$ & $0(.00)$ \\
Conspiracy ideation & $223(.93)$ & $16(.07)$ & $0(.00)$ & $0(.00)$ & $0(.00)$ \\
Controversy & $188(.79)$ & $44(.18)$ & $5(.02)$ & $2(.01)$ & $0(.00)$ \\
Indifference / Don't care & $238(1.00)$ & $1(.00)$ & $0(.00)$ & $0(.00)$ & $0(.00)$ \\
Natural & $158(.66)$ & $70(.29)$ & $10(.04)$ & $1(.00)$ & $0(.00)$ \\
Personal Choice & $232(.97)$ & $7(.03)$ & $0(.00)$ & $0(.00)$ & $0(.00)$ \\
Evidential Justifications & $46(.19)$ & $68(.28)$ & $65(.27)$ & $41(.17)$ & $19(.08)$ \\
Data / evidence & $69(.29)$ & $75(.31)$ & $55(.23)$ & $30(.13)$ & $10(.04)$ \\
Mechanism & $135(.56)$ & $76(.32)$ & $23(.10)$ & $5(.02)$ & $0(.00)$ \\
Deferential Justifications & $144(.60)$ & $71(.30)$ & $17(.07)$ & $6(.03)$ & $1(.00)$ \\
Scientist / Science & $189(.79)$ & $43(.18)$ & $5(.02)$ & $1(.00)$ & $1(.00)$ \\
Teacher / Class / Textbook & $211(.88)$ & $23(.10)$ & $4(.02)$ & $1(.00)$ & $0(.00)$ \\
Other & $207(.87)$ & $28(.12)$ & $4(.02)$ & $0(.00)$ & $0(.00)$ \\
Vague & $221(.92)$ & $17(.07)$ & $0(.00)$ & $1(.00)$ & $0(.00)$ \\
\hline & & & & &
\end{tabular}

naturally. Were people to justify their beliefs more consistently, an appeal to nature should have occurred more evenly across topics, regardless of whether participants agreed or disagreed with the scientific claim presented, because each topic has a direct connection to concepts of nature. 


\section{Belief Refutations}

Table 7 shows the frequency of belief refutation codes. In contrast to my prediction that the most common refutation response would be denial (H3), the modal refutation response was instead an appeal to further evidence, data, or research. As with the justifications, the coding scheme developed did not differentiate between referring to evidence generally or specifically. Such responses took the form of general appeals to evidence, such as "If there was scientific evidence that evolution didn't explain the evolution of species of life" (participant 162), or specific appeals to evidence, such as "Proof that the ozone isn't shrinking due to human abuse" (participant 37).

As with the belief justifications, a chi-squared goodness-of-fit analysis was conducted to assess the frequency of response types in comparison to the frequency of response types found in prior research (Shtulman, 2013). Results of the chi-squared test revealed that the present data significantly differed from the expected frequencies, $\chi^{2}(3,880)=545.91, p<.001$. As shown in Table 8, there was a higher proportion of Subjective and Evidential refutations and a lower proportion of Deferential refutations in the present study compared to Shtulman's (2013) study, whereas there was a similar proportion of Denial responses. These results refute my hypothesis (H4) that refutations that could be considered philosophically or scientifically appropriate (i.e., Evidential and Deferential) would occur less frequently than inappropriate refutations (i.e., Denial and Subjective).

Table 9 shows the frequency with which participants used each code across the four topics. Nearly half (49\%) of participants explicitly stated that for at least one topic, nothing would change their position, with $21 \%$ of participants asserting this for more than one topic. Interestingly, participants were most likely to explicitly state nothing would change their position 
Table 7

Frequency of Refutation Codes for Four Scientific Topics

\begin{tabular}{|c|c|c|c|c|c|}
\hline \multirow[b]{2}{*}{ Refutation Code } & \multicolumn{5}{|c|}{$\underline{\text { Topic }}$} \\
\hline & Evolution & $\begin{array}{l}\text { Climate } \\
\text { Change }\end{array}$ & GMOs & Vaccines & Total \\
\hline Denial & 72 & 51 & 25 & 39 & 187 \\
\hline \multicolumn{6}{|l|}{ Subjective } \\
\hline Logical & 0 & 0 & 0 & 0 & 0 \\
\hline Moral & 0 & 0 & 0 & 1 & 1 \\
\hline Religious & 36 & 0 & 0 & 0 & 36 \\
\hline Cultural Identity & 0 & 2 & 0 & 0 & 2 \\
\hline Experience & 1 & 1 & 5 & 14 & 21 \\
\hline Belief-based / Circular & 0 & 1 & 1 & 0 & 2 \\
\hline Knowledge / Education & 14 & 16 & 42 & 8 & 80 \\
\hline Conspiracy ideation & 0 & 1 & 6 & 4 & 11 \\
\hline Controversy & 1 & 0 & 2 & 3 & 6 \\
\hline Indifference / Don't care & 0 & 0 & 1 & 0 & 1 \\
\hline Natural & 0 & 2 & 0 & 0 & 2 \\
\hline Personal Choice & 0 & 0 & 0 & 0 & 0 \\
\hline Counterfactual hindsight bias & 1 & 21 & 14 & 6 & 42 \\
\hline Answering for others & 3 & 1 & 1 & 3 & 8 \\
\hline \multicolumn{6}{|l|}{ Evidential } \\
\hline Data & 70 & 95 & 109 & 126 & 400 \\
\hline Mechanism & 12 & 11 & 2 & 3 & 28 \\
\hline Unrealistic & 10 & 5 & 0 & 8 & 23 \\
\hline Methodological & 0 & 0 & 6 & 8 & 14 \\
\hline \multicolumn{6}{|l|}{ Deferential } \\
\hline Scientist / Science & 5 & 10 & 5 & 5 & 25 \\
\hline Teacher / Class / Textbook & 0 & 0 & 0 & 0 & 0 \\
\hline Other & 2 & 4 & 9 & 5 & 20 \\
\hline Clarification / Qualification & 5 & 4 & 3 & 2 & 14 \\
\hline Don't Know & 9 & 5 & 1 & 1 & 16 \\
\hline Vague & 6 & 10 & 7 & 5 & 28 \\
\hline Total & 247 & 240 & 239 & 241 & 967 \\
\hline No Answer (empty response) & 22 & 29 & 27 & 24 & 102 \\
\hline
\end{tabular}


on the topic of evolution compared to the other topics. A large majority of participants (82\%) indicated that for at least one topic, some form of evidential challenge to their position would get them to consider changing their mind, with $13 \%$ of participants stating as much for all four topics. Beyond that particular instance, and similar to the belief justification responses, this again illustrates the inconsistency with which participants respond when asked about different scientific topics. For instance, a religiously based challenge to their belief was referenced by $15 \%$ of participants, and examining Table 7 reveals this type of refutation only applies for changing peoples' minds about evolution.

Table 8

Comparison of Proportions of Refutation Types

Between Shtulman (2013) and Present Study

\begin{tabular}{lcc}
\hline Refutation Type & Shtulman (2013) & Present Study \\
\hline Denial & .21 & .21 \\
Subjective & .10 & .24 \\
Evidential & .30 & .50 \\
Deferential & .39 & .05 \\
\hline
\end{tabular}

Although the coding schemes for the belief justifications and belief refutations are nearly identical, there are two notable exceptions. First, refutations occasionally took the form of a peculiar form of hindsight bias presented as a counterfactual. For instance, Participant 6 responded to the climate change refutation question that challenging his or her position on 
Table 9

Frequency (Proportion) of Participants' Use of Each Refutation Code for None, Any, or All Scientific Topics

\begin{tabular}{|c|c|c|c|c|c|}
\hline & 0 topics & 1 topic & 2 topics & 3 topics & 4 topics \\
\hline Denial & $121(.51)$ & $67(.28)$ & $38(.16)$ & $8(.03)$ & $5(.02)$ \\
\hline Subjective Refutations & $109(.46)$ & $86(.36)$ & $24(.10)$ & $16(.07)$ & $4(.02)$ \\
\hline Logical & $239(1.00)$ & $0(.00)$ & $0(.00)$ & $0(.00)$ & $0(.00)$ \\
\hline Moral & $238(1.00)$ & $1(.00)$ & $0(.00)$ & $0(.00)$ & $0(.00)$ \\
\hline Religious & $203(.85)$ & $36(.15)$ & $0(.00)$ & $0(.00)$ & $0(.00)$ \\
\hline Cultural Identity & $237(.99)$ & $2(.01)$ & $0(.00)$ & $0(.00)$ & $0(.00)$ \\
\hline Experience & $222(.93)$ & $13(.05)$ & $4(.02)$ & $0(.00)$ & $0(.00)$ \\
\hline Belief-based / Circular & $237(.99)$ & $2(.01)$ & $0(.00)$ & $0(.00)$ & $0(.00)$ \\
\hline Knowledge / Education & $181(.76)$ & $44(.18)$ & $7(.03)$ & $6(.03)$ & $1(.00)$ \\
\hline Conspiracy ideation & $228(.95)$ & $11(.05)$ & $0(.00)$ & $0(.00)$ & $0(.00)$ \\
\hline Controversy & $233(.97)$ & $6(.03)$ & $0(.00)$ & $0(.00)$ & $0(.00)$ \\
\hline Indifference / Don't care & $238(1.00)$ & $1(.00)$ & $0(.00)$ & $0(.00)$ & $0(.00)$ \\
\hline Natural & $237(.99)$ & $2(.01)$ & $0(.00)$ & $0(.00)$ & $0(.00)$ \\
\hline Personal Choice & $239(1.00)$ & $0(.00)$ & $0(.00)$ & $0(.00)$ & $0(.00)$ \\
\hline Counterfactual hindsight bias & $202(.85)$ & $33(.14)$ & $3(.01)$ & $1(.00)$ & $0(.00)$ \\
\hline Answering for others & $234(.98)$ & $4(.02)$ & $0(.00)$ & $0(.00)$ & $1(.00)$ \\
\hline Evidential Refutations & $44(.18)$ & $58(.24)$ & $65(.27)$ & $40(.17)$ & $32(.13)$ \\
\hline Data/evidence & $50(.21)$ & $62(.26)$ & $64(.27)$ & $42(.18)$ & $21(.09)$ \\
\hline Mechanism & $213(.89)$ & $24(.10)$ & $2(.01)$ & $0(.00)$ & $0(.00)$ \\
\hline Unrealistic & $217(.91)$ & $21(.09)$ & $1(.00)$ & $0(.00)$ & $0(.00)$ \\
\hline Methodological & $227(.95)$ & $10(.04)$ & $2(.01)$ & $0(.00)$ & $0(.00)$ \\
\hline Deferential Refutations & $208(.87)$ & $20(.08)$ & $8(.03)$ & $3(.01)$ & $0(.00)$ \\
\hline Scientist / Science & $223(.93)$ & $10(.04)$ & $3(.01)$ & $3(.01)$ & $0(.00)$ \\
\hline Teacher / Class / Textbook & $239(1.00)$ & $0(.00)$ & $0(.00)$ & $0(.00)$ & $0(.00)$ \\
\hline Other & $223(.93)$ & $12(.05)$ & $4(.02)$ & $0(.00)$ & $0(.00)$ \\
\hline Clarification / Qualification & $225(.94)$ & $14(.06)$ & $0(.00)$ & $0(.00)$ & $0(.00)$ \\
\hline Don't Know & $223(.93)$ & $16(.07)$ & $0(.00)$ & $0(.00)$ & $0(.00)$ \\
\hline Vague & $218(.91)$ & $17(.07)$ & $1(.00)$ & $3(.01)$ & $0(.00)$ \\
\hline No Answer (empty response) & $197(.82)$ & $12(.04)$ & $10(.04)$ & $10(.04)$ & $10(.04)$ \\
\hline
\end{tabular}

climate change would require "If people came together and tried to end climate change." If taken at face value, the logic of this response is that if humans addressed the problem of climate 
change, this participant would stop believing in anthropogenic climate change. This is somewhat of a nonsensical response, because in order to change their position that human activity is a factor in climate change, human activity would be needed to reverse the pattern of climate change currently observed. Fifteen percent of participants made similar such declarations for at least one of the topics. As shown in Table 6, this kind of reasoning occurred at least once for each topic, though occurred most frequently in responses to the climate change item. The second additional code for the refutation question responses, although it occurred very infrequently, emerged because some participants provided refutation responses about what they think would change the minds of other people, rather than what would change their mind.

\section{Predictors of Justification and Refutation Types}

Multiple regression analyses with participants' level of agreement with the four scientific topics entered as predictor variables and the major qualitative code categories (i.e., nonjustifications, subjective justifications, evidential justifications, deferential justifications, denial, subjective refutations, evidential refutations, and deferential refutations) entered as criterion variables were conducted to examine whether participants' level of agreement with each of the four scientific claims was related to the types of open-ended responses the provided across all four topics (see Tables 10 and 11). Only statistically significant models will be discussed.

Participants who included more non-justifications in their responses had lower levels of agreement with the climate change and vaccine items, $F(4,234)=5.44, p<.001$. Participants who included more evidential justifications in their responses had higher levels of agreement with all four scientific claims, $F(4,234)=12.38, p<.001$. Participants who included more deferential justifications in their responses had higher levels of agreement with the evolution, GMO, and vaccine items, $F(4,234)=4.69, p=.001$. Participants who included more evidential 
Table 10

Frequency of Justifications Predicted by Level of Agreement with Scientific Claims

\begin{tabular}{|c|c|c|c|c|c|c|c|c|}
\hline \multirow[b]{2}{*}{ Predictors } & \multicolumn{2}{|c|}{$\frac{\text { Non- }}{\text { Justifications }}$} & \multicolumn{2}{|c|}{ Subjective } & \multicolumn{2}{|c|}{ Evidential* } & \multicolumn{2}{|c|}{ Deferential* } \\
\hline & $\beta$ & $t$ & $\beta$ & $t$ & $\beta$ & $t$ & $\beta$ & $t$ \\
\hline Evolution & -.10 & -1.51 & -.13 & -1.97 & .18 & $3.04 * *$ & .18 & $2.86 * *$ \\
\hline Climate change & -.20 & $-3.14 * *$ & .002 & .03 & .22 & $3.60 * * *$ & .08 & 1.21 \\
\hline GMO & -.04 & -.666 & -.02 & -.35 & .21 & $3.35 * *$ & .16 & $2.36 *$ \\
\hline Vaccines & -.15 & $-2.33 *$ & -.03 & -.49 & .15 & $2.51 *$ & .02 & .24 \\
\hline
\end{tabular}

Regression models with $*$ are significant at $p<.05$ level

$\mathrm{GMO}=$ Genetically modified organisms

refutations in their responses had higher levels of agreement with the evolution and climate change items, $F(4,234)=6.59, p<.001$. Finally, participants who included more deferential refutations in their responses had higher levels of agreement with the climate change item, $F(4$, 234) $=2.95, p=.021$.

Taken together, these results illustrate the relationship between participants' beliefs about science and their explicit reasoning about their beliefs. Greater agreement with scientific claims corresponds to a higher likelihood of references to objective sources of justification, such as evidence or deference to a perceived authority, supporting $\mathrm{H}_{2 \mathrm{~b}}$. A lower level of agreement with some scientific claims, specifically claims regarding climate change and vaccines, correspond to a higher likelihood of responses that do not actually justify the belief. Likewise, for participant responses about possible challenges to their belief, higher agreement with scientific claims, 
Table 11

Frequency of Refutations Predicted by Level of Agreement with Scientific Claims

\begin{tabular}{|c|c|c|c|c|c|c|c|c|}
\hline \multirow[b]{2}{*}{ Predictors } & \multicolumn{2}{|c|}{$\underline{\text { Denial }}$} & \multicolumn{2}{|c|}{$\underline{\text { Subjective }}$} & \multicolumn{2}{|c|}{$\underline{\text { Evidential* }}$} & \multicolumn{2}{|c|}{$\underline{\text { Deferential* }}$} \\
\hline & $\beta$ & $t$ & $\beta$ & $t$ & $\beta$ & $t$ & $\beta$ & $t$ \\
\hline Evolution & -.05 & -.83 & -.17 & -2.62 & .22 & $3.41 * * *$ & .12 & 1.78 \\
\hline Climate change & .06 & .93 & -.08 & -1.29 & .15 & $2.34 *$ & .13 & $2.05^{*}$ \\
\hline GMO & -.08 & -1.19 & .04 & .65 & .12 & 1.87 & .08 & 1.12 \\
\hline Vaccines & -.02 & -.33 & .03 & .46 & .06 & .93 & .07 & 1.07 \\
\hline
\end{tabular}

Note: $N=239, * p<.05 . * * p<.01 . * * * p<.001$

Regression models with $*$ are significant at $p<.05$ level

$\mathrm{GMO}=$ Genetically modified organisms

particularly those about evolution and climate change, corresponded to more references to objective sources of refutation, such as contradictory evidence or deferring to changing views of experts, supporting $\mathrm{H}_{4 \mathrm{~b}}$. These results suggest a connection between agreement with science and awareness of what constitutes valid or appropriate reasoning for scientific conclusions. That is to say, it is potentially the case that individuals who agree more strongly with scientific claims may better understand the epistemological commitments of science better than individuals who disagree with scientific claims. 


\section{CHAPTER IV: GENERAL DISCUSSION}

The present study was designed to expand on prior research on variables that influence agreement with scientific claims by examining what reasons people provide for their beliefs on politically polarized socio-scientific issues. The gap between how the general public and professional scientists accept certain scientific issues, such as those explored here, is large (Funk

\& Rainie, 2015), and efforts to improve acceptance of science by addressing an assumed information deficit in the public are not always effective (Gauchat, 2012; Kahan, 2006; Miller, 2001). Instead, researchers have found better predictors of the acceptance of various scientific claims in social, cognitive, and personality variables such as cognitive style, religious affiliation, political ideology, and cultural worldview (Gervais, 2015; Kahan 2015; Lewandowsky et al., 2013a; Lindeman, 2011; Lobato et al., 2014; Majima, 2015; Nisbet et al., 2015; Shen \& Gromet, 2015). One substantial gap in the literature is an examination of the reasons people provide for their beliefs regarding scientific conclusions. The present study adds to that literature.

Findings from this study supported the following hypotheses: $\left(\mathrm{H} 1_{\mathrm{a}}\right)$ A greater predisposition towards an analytical (i.e., Type 2) cognitive style predicted a higher level of agreement with scientific claims; $\left(\mathrm{H} 2_{\mathrm{a}}\right)$ For all topics and all levels of agreement, there were fewer scientifically acceptable justifications compared to justifications that were not scientifically or philosophically acceptable across; $\left(\mathrm{H} 2_{b}\right)$ Higher levels of agreement with a scientific claim predicted the use of a scientifically or philosophically acceptable justification; and $\left(\mathrm{H} 4_{b}\right)$ Higher levels of agreement with a scientific claim predicted refutations that were scientifically or philosophically acceptable. 
Only partial support was found for the following hypotheses: $\left(\mathrm{H} 1_{\mathrm{d}-\mathrm{e}}\right)$ Stronger political conservatism predicted a lower level of agreement with all four scientific claims relative to political liberalism rather than conservatives expressing lower agreement with claims about evolution and climate change relative to GMO safety and vaccine safety and liberals expressing lower agreement with GMO safety and vaccine safety relative to agreement with evolution and climate change.

No support was found for the following hypotheses: $\left(\mathrm{H} 1_{\mathrm{b}}\right)$ A greater predisposition towards an intuitive (i.e., Type 1) cognitive style did not predict a lower level of agreement with scientific claims; $\left(\mathrm{H} 1_{\mathrm{c}}\right)$ A greater predisposition to conspiracy ideation did not predict a lower level of agreement with scientific claims; $\left(\mathrm{H} 1_{\mathrm{f}}\right)$ More frequent attendance of religious services did not predict a lower level of agreement with scientific claims about evolution; (H3) Denial was not the most common refutation response; $\left(\mathrm{H} 4_{\mathrm{a}}\right)$ Scientifically or philosophically acceptable refutations were not less frequent refutation responses than refutations that are not scientifically or philosophically.

The following hypotheses were unable to be examined: $\left(\mathrm{H} 2_{c} ; \mathrm{H} 4_{c}\right)$ Due to low internal reliability, I could not use participant scores on the Cultural Worldview Scale to predict their justifications and refutations.

Findings from the canonical correlation analysis showed that lower agreement with all four scientific statements was predicted by a low analytical thinking style, as measured by the Rational-Experiential Inventory (Norris \& Epstein, 2013), and self-reported political conservatism. However, this result may only hold for politicized scientific topics or topics that are considered controversial outside of their respective disciplines, such as the ones studied here. 
With this cautionary interpretation in mind, the present results do hint at two ways in which these topics can be discussed or taught in a manner that may improve agreement with scientific consensus. First, educators and pop culture science advocates may wish to present and discuss these topics in a way that diminishes any association with a socio-political identity. Instead, presentation of these topics could, for instance, only attempt to stick to the data so as not to make salient a potentially anti-scientific aspect of one's individual or group identity. This suggestion aligns with the conclusions by Shen and Gromet (2015) regarding framing of a less controversial domain of science. They found lower support for the discipline of neurolaw among Republicans when the issue was framed in a way that benefits the defense side of criminal law than when the issue was framed as benefiting criminal prosecutors or was framed in a neutral fashion. The manner in which scientific topics are framed may be more influential in how people think about a topic than what the topic itself simply is. Second, the present results imply a need for better training and education to encourage people to rely more on a reflective, effortful, analytic style of thinking when considering scientific topics. Adopting the perspective of a scientist, a profession where reflective and analytical thinking is encouraged, has been linked to better performance on physics tasks (Amsel \& Johnson, 2008). A more explicit educational curriculum that teaches people what thinking like a scientist entails, how to adopt the identity of a scientist, and what the culture of science is may be beneficial for improving scientific literacy (see also Wynne, 2006).

Curiously, the Cultural Worldview Scale did not reach acceptable standards of internal reliability in the present sample, precluding analysis of the relationship between cultural worldview and agreement with scientific claims. The lack of internal reliability for this measure is potentially due to differences in sample characteristics between the present sample and those 
used by Kahan and colleagues $(2007,2009,2012)$ when developing the scale. Samples recruited in Kahan and colleagues' studies were either large (exceeding 1,500 participants; see Kahan et al., 2007, 2009) or were more representative of the general population than the present sample (e.g., Kahan et al., 2009, 2012). By contrast, the present sample size was more modest $(N=244)$, and was comprised of undergraduate students and university staff. Cronbach's alpha is a parameter representing the ratio of the sum of item variance to the total score variance (Streiner, 2003). A large, heterogeneous sample is more likely to produce high alpha estimates simply because heterogeneous samples increase the variance of the total scores. Cronbach's alpha allows researchers to estimate measurement error within a given sample, such that as reliability increases the amount of variance attributable to measurement error for the sample decreases (Tavakol \& Dennick, 2011). This is done by squaring the reliability parameter and subtracting from 1. The Cultural Worldview Scale subscale reliabilities were .52 for the IndividualismCommunitarianism subscale and .59 for the Hierarchical-Egalitarianism subscale, resulting in variance attributable to measurement error for each subscale as $83 \%$ and $65 \%$ respectively. I considered this unacceptably high and, therefore, was unable to use participants' scores on Cultural Worldview Scale to examine $\mathrm{H} 2_{\mathrm{c}}$ and $\mathrm{H} 4_{\mathrm{c}}$.

Beyond providing additional data about the relationship between individual difference variables and acceptance or rejection of science, the present study was also designed to help fill a gap in the literature on why people hold the beliefs they do about scientific claims (see also, Kuhn, 1991). Novel to the present study is a qualitative examination of why people say they accept or reject scientific claims. Little research has attempted to investigate this aspect of beliefs about science (e.g., Shtulman, 2013), but comparison between prior research and the present study can still be made. 
Shtulman (2013) reported findings that showed people tend to reason about beliefs in scientific and various non-scientific (e.g., paranormal, religious) phenomena similarly. Largely, participants in his study justified their beliefs by deferring to other sources of information, such as authority figures, sacred texts, experts, and teachers. In the present study, participants justified their position on scientific claims largely by referring to subjective sources of information, such as personal experience (or lack thereof) with the phenomena, their own knowledge (or lack thereof) about the topic, circular reasoning, cultural and religious identity, or appeals to nature. Referencing some form of empirical source of evidence, such as evidence or causal mechanism, was the second most frequent type of response. Additionally, there were significantly more clarification and qualification non-justifications in the present study relative to those found in Shtulman's research. These differences in the pattern of results between Shtulman's research and the present study are likely due to the different topics participants responded to. Shtulman examined peoples' justifications for belief in the existence of particular phenomena, such as electrons, genes, or evolution. By contrast, here I examined peoples' justifications for their level of agreement with scientific conclusions, such as evolutionary theory being the best current explanation for the existence of the variety of species or that medical research has shown that childhood vaccinations are largely safe and effective. This difference may predispose people to think of the topic in a more complex fashion, because level of agreement with scientific conclusions on these topics does have some connection to policy positions people take. These socio-scientific issues are related to peoples' opinions on what material should be taught in science classrooms, what kind of industrial regulations or environmental protections should be adopted, what kind of information for customers should be provided on food packaging, and what kind of healthcare policies for child care should be in place. This may explain the large 
difference in proportion of clarifications between the two studies. Here, the prompts that participants responded to may have primed participants to elaborate more on their specific beliefs than what could be conveyed by a simple Likert-response, in contrast to a question inquiring about belief in just the existence or non-existence of phenomena.

Results from this qualitative analysis also demonstrate some of the ways in which scientific claims, particularly allegedly controversial claims, are thought of by non-specialists. Though participants in this study reasoned across these scientific claims in a largely inconsistent fashion, there were topic-specific patterns of reasoning that emerged. For evolution, it was common for participants to reference religion in some fashion, both in their justifications for or against the claim and in their thinking about possible refutations. On the topic of climate change, participants referenced the natural state of the climate. For genetically modified organisms, participants commonly made reference to the idea that what is natural is inherently better than what is artificial as well as referencing their own level of knowledge regarding the topic. Regarding the topic of vaccines, participants commonly made subjective justifications such as direct experience and referencing the topic as controversial. Strategies for promoting improved scientific literacy should be developed with the awareness of how people think about these topics, although it should be noted that the specific wording of the scientific claims used in this survey may have differentially primed different ways in which participants responded to the open-ended questions. For instance, in the Evolution item, the phrase "best explanation" may have primed individuals to think about prospective explanations, of which religiously based explanations (e.g., creationism or intelligent design) are commonly associated. For the Climate Change item, the phrase "human activity is contributing to" might have primed participants to think in terms of causal mechanism. Future research in this area may be able to explore this 
potential confound by wording scientific conclusions for participants to respond to differently, either by being as neutral as possible or by deliberately wording statements in such a way as to prime other justifications.

In sum, the present study is a necessary step towards filling a large gap in the research on attitudes and beliefs about science. The research was designed to further investigate individual difference variables that might be predict agreement with science, as well as to provide needed qualitative research to explore in more detail the reasons people provide for their beliefs about scientific topics. An analytical cognitive style and stronger political liberalism were predictive of higher agreement with all four scientific claims studied. Higher agreement with scientific claims regarding evolution, climate change, GMOs, and vaccines was also related to a greater frequency of referencing justifications and refutations that are more scientifically or philosophically valid forms of reasoning, such as appealing to evidence or deferring to expertise. Furthermore, participants in the present study were found to reason inconsistently across all four topics, providing unique clusters of response types for the different topics. Additionally, the findings illustrate the need for further qualitative research into the development and maintenance of attitudes about science. Being able to tailor education about science to the manner in which people think about science may improve scientific literacy, but doing so requires more research into why people hold the beliefs they do about science. 


\section{REFERENCES}

Amsel, E., \& Johnston, A. (2008). The role of imagination in conceptual change. Paper presented at the Annual Meeting of the American Educational Research Association (New York, NY).

Barnes, R. M., \& Church, R. A. (2013). Proponents of creationism but not proponents of evolution frame the origins debate in terms of proof. Science \& Education, 22, 577-603.

Bauer, H. H. (1994). Scientific literacy and the myth of the scientific method. University of Illinois Press.

Bem, D. J. (2011). Feeling the future: experimental evidence for anomalous retroactive influences on cognition and affect. Journal of Personality and Social Psychology, 100, 407.

Blank, J. M., \& Shaw, D. (2015). Does Partisanship Shape Attitudes toward Science and Public Policy? The Case for Ideology and Religion. The ANNALS of the American Academy of Political and Social Science, 658, 18-35.

Boudry, M., Blancke, S., \& Pigliucci, M. (2014). What makes weird beliefs thrive? The epidemiology of pseudoscience. Philosophical Psychology. Advance online publication. doi: 10.1080/09515089.2014.971946

Boudry, M., \& Braeckman, J. (2011). Immunizing strategies and epistemic defense mechanisms. Philosophia, 39, 145-161.

Boudry, M., \& Braeckman, J. (2012). How convenient! The epistemic rationale of self-validating belief systems. Philosophical Psychology, 25, 341-364. 
Bouvet, R., \& Bonnefon, J. F. (2015). Non-Reflective thinkers are predisposed to attribute supernatural causation to uncanny experiences. Personality and Social Psychology Bulletin, 41, 955-961.

Bruder, M., Haffke, P., Neave, N., Nouripanah, N., \& Imhoff, R. (2013). Measuring individual differences in generic beliefs in conspiracy theories across cultures: Conspiracy Mentality Questionnaire. Frontiers in Psychology, 4, 225. doi:10.3389/fpsyg.2013.00225

Cleland, C. E. (2001). Historical science, experimental science, and the scientific method. Geology, 29, 987-990.

Cleland, C. E., and Brindell, S. (2013). Science and Messy, Uncontrollable Nature. In M. Pigliucci \& M. Boudry (Eds.), Philosophy of Pseudoscience: Reconsidering the Demarcation Problem, (pp. 183 - 202) Chicago: Chicago University Press.

Corbin, J., \& Strauss, A. (2014). Basics of qualitative research: Techniques and procedures for developing grounded theory. Sage publications.

Evans, J. S. B. (2008). Dual-processing accounts of reasoning, judgment, and social cognition. Annual Review of Psychology, 59, 255-278.

Faul, F., Erdfelder, E., Lang, A. G., \& Buchner, A. (2007). G*Power 3: A flexible statistical power analysis program for the social, behavioral, and biomedical sciences. Behavior Research Methods, 39, 175-191.

Funk, C., \& Rainie, L. (2015). Public and Scientists' Views on Science and Society. Pew Research Center http://www.pewinternet.org/2015/01/29/public-and-scientists-views-onscience-and-society.

Gauchat, G. (2012). Politicization of science in the public sphere a study of public trust in the United States, 1974 to 2010. American Sociological Review, 77, 167-187. 
Gervais, W. M. (2015). Override the controversy: Analytic thinking predicts endorsement of evolution. Cognition, 142, 312-321.

Goertzel, T. (1994). Belief in conspiracy theories. Political Psychology, 15, 731-742.

Gross, A. G. (1994). The roles of rhetoric in the public understanding of science. Public Understanding of Science, 3, 3-23.

Kahan, D. M. (2012). Why we are poles apart on climate change. Nature, 488, 255.

Kahan, D. M. (2015). Climate-science communication and the measurement problem. Political Psychology, 36), 1-43.

Kahan, D. M., \& Braman, D. (2006). Cultural cognition and public policy. Yale Law \& Policy Review, 24, 149-172.

Kahan, D. M., Braman, D., Gastil, J., Slovic, P., \& Mertz, C. K. (2007). Culture and identityprotective cognition: Explaining the white-male effect in risk perception. Journal of Empirical Legal Studies, 4, 465-505.

Kahan, D. M., Braman, D., Slovic, P., Gastil, J., \& Cohen, G. (2009). Cultural cognition of the risks and benefits of nanotechnology. Nature Nanotechnology, 4, 87-90.

Kahan, D. M., Hoffman, D. A., Braman, D., Evans, D., \& Rachlinski, J. J. (2012). They saw a protest: Cognitive illiberalism and the speech-conduct distinction. Stanford Law Review, $64,851$.

Kahneman, D. (2011). Thinking, Fast and Slow. Macmillan.

Koslowski, B. (1996). Theory and Evidence: The Development of Scientific Reasoning. MIT Press.

Kuhn, D. (1991). The Skills of Argument. Cambridge University Press. 
Kuhn, D. (1999). A developmental model of critical thinking. Educational Researcher, 28, 1646.

Kuhn, D. (2000). Metacognitive development. Current Directions in Psychological Science, 9 , $178-181$.

Kuhn, D. (2009). The importance of learning about knowing: Creating a foundation for development of intellectual values. Child Development Perspectives, 3, 112-117.

Kunda, Z. (1990). The case for motivated reasoning. Psychological Bulletin, 108, 480-498.

Lindeman, M. (2011). Biases in intuitive reasoning and belief in complementary and alternative medicine. Psychology and Health, 26, 371-382.

Lindeman, M., \& Aarnio, K. (2007). Superstitious, magical, and paranormal beliefs: An integrative model. Journal of Research in Personality, 41, 731-744.

Levin, I. P., Schneider, S. L., \& Gaeth, G. J. (1998). All frames are not created equal: A typology and critical analysis of framing effects. Organizational Behavior and Human Decision Processes, 76, 149-188.

Lewandowsky, S., Gignac, G. E., \& Oberauer, K. (2013a). The role of conspiracist ideation and worldviews in predicting rejection of science. PLoS One, 8, e75637.

Lewandowsky, S., Oberauer, K., \& Gignac, G. E. (2013b). NASA faked the moon landingtherefore,(climate) science is a hoax an anatomy of the motivated rejection of science. Psychological Science, 24, 622-633.

Lobato, E. J. C., Mendoza, J., Sims, V. K., \& Chin, M. G. (2014). Examining the relationship between conspiracy theories, paranormal beliefs, and pseudoscience acceptance. Applied Cognitive Psychology, 28, 617-625. 
Lobato, E. J. C. \& Zimmerman, C. (2015, April). Belief in the unbelievable: Individual differences in tendencies to believe pseudoscience, paranormal, and conspiracy theories. Poster session presented at the 2015 Annual Meeting of the Midwestern Psychological Association, Chicago, IL.

Majima, Y. (2015). Belief in pseudoscience, cognitive style and science literacy. Applied Cognitive Psychology, 29, 552-559.

McComas, W. F. (1996). Ten myths of science: Reexamining what we think we know about the nature of science. School Science and Mathematics, 96, 10-16.

Miller, S. (2001). Public understanding of science at the crossroads. Public Understanding of Science, 10, 115-120.

Munro, G. D. (2010). The scientific impotence excuse: Discounting belief-threatening scientific abstracts. Journal of Applied Social Psychology, 40, 579-600.

National Research Council. (2010). Exploring the intersection of science education and 21st century skills: A workshop summary. Washington DC: National Academies Press.

National Research Council. (2012). A Framework for K-12 Science Education: Practices, Crosscutting Concepts, and Core Ideas. Washington, DC: National Academies Press.

Nisbet, E. C., Cooper, K. E., \& Garrett, R. K. (2015). The Partisan Brain How Dissonant Science Messages Lead Conservatives and Liberals to (Dis)Trust Science. The ANNALS of the American Academy of Political and Social Science, 658, 36-66.

Norris, P., \& Epstein, S. (2011). An experiential thinking style: Its facets and relations with objective and subjective criterion measures. Journal of Personality, 79, 1043-1080.

Pennycook, G., Cheyne, J. A., Seli, P., Koehler, D. J., \& Fugelsang, J. A. (2012). Analytic cognitive style predicts religious and paranormal belief. Cognition, 123, 335-346. 
Pigliucci, M. (2013). The demarcation problem: a (belated) response to Laudan. In M. Pigliucci \& M. Boudry (Eds.), Philosophy of Pseudoscience: Reconsidering the Demarcation Problem, (pp. 9 - 28) Chicago: Chicago University Press.

Rouder, J. N., \& Morey, R. D. (2011). A Bayes factor meta-analysis of Bem’s ESP claim. Psychonomic Bulletin \& Review, 18, 682-689.

Schwarzkopf, D. S. (2014). We should have seen this coming. Frontiers in Human Neuroscience, 8, 332 .

Shen, F. X., \& Gromet, D. M. (2015). Red states, blue states, and brain states: Issue framing, partisanship, and the future of neurolaw in the United States. The ANNALS of the American Academy of Political and Social Science, 658, 86-101.

Shtulman, A. (2013). Epistemic similarities between students' scientific and supernatural beliefs. Journal of Educational Psychology, 105, 199-212.

Stanovich, K. E., \& Toplak, M. E. (2012). Defining features versus incidental correlates of Type 1 and Type 2 processing. Mind \& Society, 11, 3-13.

Streiner, D. L. (2003). Starting at the beginning: An introduction to coefficient alpha and internal consistency. Journal of Personality Assessment, 80, 99-103.

Still, A., \& Dryden, W. (2004). The social psychology of "pseudoscience": A brief history. Journal for the Theory of Social Behaviour, 34, 265-290.

Tabachnick, B. G., \& Fidell, L. S. (2007). Using Multivariate Statistics, 5th ed. Boston: Pearson. Tavakol, M., \& Dennick, R. (2011). Making sense of Cronbach's alpha. International Journal of Medical Education, 2, 53-55.

Thagard, P. (1989). Explanatory coherence. Behavioral and Brain Sciences, 12, 435-467. 
Wood, M. J., Douglas, K. M., \& Sutton, R. M. (2012). Dead and alive: Beliefs in contradictory conspiracy theories. Social Psychological and Personality Science, 3, 767-773.

Wynne, B. (2006). Public engagement as a means of restoring public trust in science-hitting the notes, but missing the music?. Public Health Genomics, 9, 211-220.

Zimmerman, C., Bisanz, J., \& Bisanz, G. L. (1998). Everyday scientific literacy: Do students use information about the social context and methods of research to evaluate news briefs about science?. Alberta Journal of Educational Research, 44, 188. 


\section{APPENDIX A: SCIENTIFIC ITEMS SURVEY}

Instructions: This is a brief survey of your own beliefs and attitudes on a variety of subjects of public, political, and scientific interest. There are no correct or incorrect answers. We are only interested in your opinions about these topics. Please rate how much you agree or disagree with the following statements on a scale of 1 to 6 , where 1 indicates that you do not agree with the statement at all and 6 indicates that you completely agree with the statement. After responding to each statement, you will be asked to answer two open-ended questions.

1) Biological evolution is the best explanation for explaining the varieties of species of life.
1
2
3
4
5
6

(I do not

(I agree

agree with

completely

this statement

with this

at all)

statement)

1a) What are your reasons for your position on this topic? (open-ended)

1b) What possible reasons can you think of that would change your position on [topic]? (open-ended)

2) The earth is experiencing a period of global climate change that human activity is contributing

to.

1

2

(I do not

agree with
3

4

5

6

(I agree

completely 
this statement

at all) with this

statement)

2a) What are your reasons for your position on this topic? (open-ended)

2b) What possible reasons can you think of that would change your position on [topic]? (open-ended)

3) Genetically modified foods (also known as GM or GMO foods) are largely safe for human consumption.
1
2
3
4
5
6

(I do not

(I agree

agree with

completely

this statement

with this

at all)

statement)

3a) What are your reasons for your position on this topic? (open-ended)

3b) What possible reasons can you think of that would change your position on [topic]? (open-ended)

4) Medical research has demonstrated that childhood vaccinations are largely safe and effective.

1

2

3

(I do not

agree with

this statement

at all)
4

5

6

(I agree

completely

with this

statement) 
4a) What are your reasons for your position on this topic? (open-ended)

4b) What possible reasons can you think of that would change your position on [topic]? (open-ended) 
APPENDIX B: RATIONAL-EXPERIENTIAL INVENTORY (NORRIS \& EPSTEIN, 2011)

Instructions - Please select the response that best corresponds to the way you feel concerning the following questions or statements.

1 I enjoy problems that require hard thinking.

$\begin{array}{lllll}1 & 2 & 3 & 4 & 5\end{array}$

Strongly Disagree Strongly Agree

2 I am not very good in solving problems that require careful logical analysis.

$\begin{array}{lllll}1 & 2 & 3 & 4 & 5\end{array}$

Strongly Disagree Strongly Agree

3 I enjoy intellectual challenges.

$\begin{array}{ccccc}1 & 2 & 3 & 4 & 5 \\ \text { Strongly Disagree } & & & & \text { Strongly Agree }\end{array}$

4 I prefer complex to simple problems.

$\begin{array}{ccccc}1 & 2 & 3 & 4 & 5 \\ \text { Strongly Disagree } & & & & \text { Strongly Agree }\end{array}$

5 I don't like to have to do a lot of thinking.

$\begin{array}{ccccc}1 & 2 & 3 & 4 & 5 \\ \text { Strongly Disagree } & & & & \text { Strongly Agree }\end{array}$

6 Reasoning things out carefully is not one of my strong points.

$\begin{array}{ccccc}1 & 2 & 3 & 4 & 5 \\ \text { Strongly Disagree } & & & & \text { Strongly Agree }\end{array}$

7 I am not a very analytical thinker.

$\begin{array}{ccccc}1 & 2 & 3 & 4 & 5 \\ \text { Strongly Disagree } & & & & \text { Strongly Agree }\end{array}$

$8 \mathrm{I}$ try to avoid situations that require thinking in depth about something.

$\begin{array}{ccccc}1 & 2 & 3 & 4 & 5 \\ \text { Strongly Disagree } & & & & \text { Strongly Agree }\end{array}$


9 I am much better at figuring things out logically than most people.

\begin{tabular}{|c|c|c|c|c|}
\hline 1 & 2 & 3 & 4 & 5 \\
\hline Strongly Disagree & & & & Strongly Agree \\
\hline
\end{tabular}

10 I have a logical mind.
1
23
Strongly Disagree
$\begin{array}{ll}3 & 4\end{array}$
45

11 Using logic usually works well for me in figuring out problems in my life.
1
2
3
4
5
Strongly Disagree
Strongly Agree

12 Knowing the answer without understanding the reasoning behind it is good enough for me.

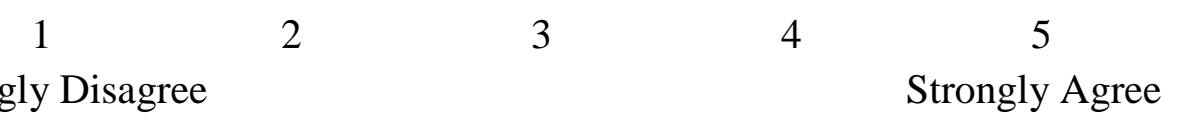

Strongly Disagree

13 I enjoy reading things that evoke visual images.

\begin{tabular}{|c|c|c|c|c|}
\hline 1 & 2 & 3 & 4 & 5 \\
\hline Strongly Disagree & & & & Strongly Agree \\
\hline
\end{tabular}

14 I enjoy imagining things.

$\begin{array}{lllll}1 & 3 & 4 & 5\end{array}$

Strongly Disagree

Strongly Agree

15 I can clearly picture or remember some sculpture or natural object (not alive) that I think is very beautiful.
1
2
3
4
5

Strongly Disagree

Strongly Agree

16 I identify strongly with characters in movies or books I read.
1

$$
2
$$
3
4
5

Strongly Disagree

Strongly Agree

17 I tend to describe things by using images or metaphors, or creative comparisons. 

1
2
3
4
5

Strongly Disagree

Strongly Agree

18 Art is really important to me.
1
2
3
4
5

Strongly Disagree

Strongly Agree

19 Sometimes I like to just sit back and watch things happen.
1
2
3
4
5

Strongly Disagree

Strongly Agree

20 I have favorite poems and paintings that mean a lot to me.
1
2
3
4
5

Strongly Disagree

Strongly Agree

21 When I travel or drive anywhere, I always watch the landscape and scenery.
1
2
3
4
5

Strongly Disagree

Strongly Agree

22 I almost never think in visual images.
1
2
3
4
5

Strongly Disagree

Strongly Agree

23 My emotions don't make much difference in my life.
1
2
3
4
5

Strongly Disagree

Strongly Agree

24 Emotions don't really mean much: they come and go.
1
2
3
4
5

Strongly Disagree

Strongly Agree

25 When I have a strong emotional experience, the effect stays with me for a long time. 

1
2
3
4
5

Strongly Disagree

Strongly Agree

26 When I'm sad, it's often a very strong feeling.
1
2
3
4
5

Strongly Disagree

Strongly Agree

27 Things that make me feel emotional don't seem to affect other people as much.
1
2
3
4
5

Strongly Disagree

Strongly Agree

28 Everyday experiences often evoke strong feelings in me.
1
2
3
4
5

Strongly Disagree

Strongly Agree

29 I'd rather be upset sometimes and happy sometimes, than always feel calm.
1
2
3
4
5

Strongly Disagree

Strongly Agree

30 I don't react emotionally to scary movies or books as much as most people do.
1
2
3
4
5

Strongly Disagree

Strongly Agree

31 My anger is often very intense.
1
2
3
4
5

Strongly Disagree

Strongly Agree

32 When I'm happy, the feeling is usually more like contentment than like exhilaration or excitement.
1
2
3
4
5

Strongly Disagree

Strongly Agree 
33 I like to rely on my intuitive impressions.
1
2
3
4
5

Strongly Disagree

Strongly Agree

34 I often go by my instincts when deciding on a course of action.

$\begin{array}{llllll}1 & 2 & 3 & 4 & 5\end{array}$

Strongly Disagree

Strongly Agree

35 I don't think it is a good idea to rely on ones intuition for important decisions.

1

2

3

4

5

Strongly Disagree

Strongly Agree

36 I trust my initial feelings about people.
1
2
3
4
5

Strongly Disagree

Strongly Agree

37 I tend to use my heart as a guide for my actions.
1
2
3
4
5

Strongly Disagree

Strongly Agree

38 I enjoy learning by doing something, instead of figuring it out first.

$\begin{array}{llllll}1 & 2 & 3 & 4 & 5\end{array}$

Strongly Disagree

Strongly Agree

39 I can often tell how people feel without them having to say anything.
1
2
3
4
5

Strongly Disagree

Strongly Agree

40 I generally don't depend on my feelings to help me make decisions.

1

2

3

4

5

Strongly Disagree

Strongly Agree 
41 For me, descriptions of actual people's experiences are more convincing than discussions about "facts."
1
2
3
4
5

Strongly Disagree

Strongly Agree

42 I'm not a very spontaneous person.

1

$2 \quad 3$

34

5

Strongly Disagree

Strongly Agree 
APPENDIX C: CULTURAL WORLDVIEW QUESTIONNAIRE (KAHAN ET AL., 2012)

A. Individualism

Instructions - People in our society often disagree about how far to let individuals go in making decisions for themselves. How strongly do you agree or disagree with each of these statements? [Possible responses: strongly disagree, moderately disagree, slightly disagree, slightly agree, moderately agree, strongly agree]

1. The government interferes far too much in our everyday lives.

2. Sometimes the government needs to make laws that keep people from hurting themselves.

3. It's not the government's business to try to protect people from themselves.

4. The government should stop telling people how to live their lives.

5. The government should do more to advance society's goals, even if that means limiting the freedom and choices of individuals.

6. Government should put limits on the choices individuals can make so they don't get in the way of what's good for society.

B. Hierarchy

Instructions - People in our society often disagree about issues of equality and discrimination. How strongly do you agree or disagree with each of these statements?

[Possible responses: strongly disagree, moderately disagree, slightly disagree, slightly agree, moderately agree, strongly agree]

1. We have gone too far in pushing equal rights in this country.

2. Our society would be better off if the distribution of wealth was more equal.

3. We need to dramatically reduce inequalities between the rich and the poor, whites and people of color, and men and women. 
4. Discrimination against minorities is still a very serious problem in our society.

5. It seems like blacks, women, homosexuals and other groups don't want equal rights, they want special rights just for them.

6. Society as a whole has become too soft and feminine. 


\section{APPENDIX D: CONSPIRACY MENTALITY QUESTIONNAIRE (BRUDER ET AL., 2013)}

Instructions: For each of the statements below, please use the respective rating scale to indicate

how likely it is in your opinion that the statement is true. Remember that there are no

“objectively" right or wrong answers and that we are interested in your personal opinion.

1) I think that many very important things happen in the world, which the public is never informed about.

\begin{tabular}{|l|c|c|c|c|c|c|c|c|c|c|}
\hline \multicolumn{1}{|c|}{$0 \%$} & $10 \%$ & $20 \%$ & $30 \%$ & $40 \%$ & $50 \%$ & $60 \%$ & $70 \%$ & $80 \%$ & $90 \%$ & $100 \%$ \\
\hline certainly & extremely & very & unlikely & somewhat & undecided & somewhat & likely & very & extremely & certain \\
not & unlikely & unlikely & & unlikely & & likely & & likely & likely \\
\hline
\end{tabular}

2) I think that politicians usually do not tell us the true motives for their decisions.

\begin{tabular}{|c|l|l|c|c|c|c|c|c|c|c|}
\hline \multicolumn{1}{|c|}{$0 \%$} & $10 \%$ & $20 \%$ & $30 \%$ & $40 \%$ & $50 \%$ & $60 \%$ & $70 \%$ & $80 \%$ & $90 \%$ & $100 \%$ \\
\hline certainly & extremely & very & unlikely & somewhat & undecided & somewhat & likely & very & extremely & certain \\
not & unlikely & unlikely & & unlikely & & likely & & likely & likely \\
\hline
\end{tabular}

3) I think that government agencies closely monitor all citizens.

\begin{tabular}{|l|l|l|l|l|l|l|l|l|l|l|}
\hline \multicolumn{1}{|c|}{$0 \%$} & $10 \%$ & $20 \%$ & $30 \%$ & $40 \%$ & $50 \%$ & $60 \%$ & $70 \%$ & $80 \%$ & $90 \%$ & $100 \%$ \\
\hline certainly & extremely & very & unlikely & somewhat & undecided & somewhat & likely & very & extremely & certain \\
not & unlikely & unlikely & & unlikely & & likely & & likely & likely \\
\hline
\end{tabular}

4) I think that events which superficially seem to lack a connection are often the result of secret activities.

\begin{tabular}{|c|c|c|c|c|c|c|c|c|c|c|}
\hline $0 \%$ & $10 \%$ & $20 \%$ & $30 \%$ & $40 \%$ & $50 \%$ & $60 \%$ & $70 \%$ & $80 \%$ & $90 \%$ & $100 \%$ \\
\hline $\begin{array}{l}\text { certainly } \\
\text { not }\end{array}$ & $\begin{array}{l}\text { extremely } \\
\text { unlikely }\end{array}$ & $\begin{array}{l}\text { very } \\
\text { unlikely }\end{array}$ & unlikely & $\begin{array}{l}\text { somewhat } \\
\text { unlikely }\end{array}$ & undecided & $\begin{array}{l}\text { somewhat } \\
\text { likely }\end{array}$ & likely & $\begin{array}{l}\text { very } \\
\text { likely }\end{array}$ & $\begin{array}{l}\text { extremely } \\
\text { likely }\end{array}$ & certain \\
\hline
\end{tabular}

5) I think that there are secret organizations that greatly influence political decisions.

\begin{tabular}{|c|c|c|c|c|c|c|c|c|c|c|}
\hline \multicolumn{1}{|c|}{$0 \%$} & $10 \%$ & $20 \%$ & $30 \%$ & $40 \%$ & $50 \%$ & $60 \%$ & $70 \%$ & $80 \%$ & $90 \%$ & $100 \%$ \\
\hline certainly & extremely & very & unlikely & somewhat & undecided & somewhat & likely & very & extremely & certain \\
not & unlikely & unlikely & & unlikely & & likely & & likely & likely \\
\hline
\end{tabular}




\section{APPENDIX E: DEMOGRAPHICS QUESTIONNAIRE}

What is your age?

What is your gender identity?

- Female

- Male

- Other (please specify)

What is your racial/ethnic background?

- Black, non-Hispanic: A person having origins in any of the Black racial groups of Africa (except those of Hispanic origin)

- Hispanic: A person of Mexican, Puerto Rican, Cuban, Central, or South America, or other Spanish culture or origin, regardless of race

- Asian or Pacific Islander: A person having origins in any of the original peoples of the Far East, Southeast Asia, the Indian subcontinent or the Pacific Islands

- American Indian or Alaskan Native: A person having origins in any of the original peoples of North America, and who maintains cultural identification through tribal affiliation or community recognition

- White, non-Hispanic: A person having origins in any of the original peoples of Europe, North Africa, or the Middle East

- Other (please specify)

- Prefer not to answer

What is your current religious affiliation?

- Catholic

- Muslim

- Jewish

- Hindu

- Buddhist

- Protestant (e.g., Baptist, Lutheran, Methodist, etc.)

- No religion (e.g., atheist, agnostic, etc.)

- Other (please specify)

- Prefer not to answer

How frequently do you attend religious services?

- Never

- At least once per year

- At least once per month

- At least once per week

- Every day

Overall, which best describes your current political ideology?

- Strongly liberal

- Moderately liberal 
- Mildly liberal

- Centrist

- Mildly conservative

- Moderately conservative

- Strongly conservative

- Other (please specify)

- Prefer not to answer

What is your current political party affiliation?

- Democratic party

- Republican party

- Independent

- Other (please specify)

- Prefer not to answer 


\section{APPENDIX F: CODING SCHEME FOR OPEN-ENDED RESPONSES}

\begin{tabular}{|c|c|}
\hline Justification Codes & Prototypical Example (Participant \#, Topic) \\
\hline \multicolumn{2}{|l|}{ Non-justification } \\
\hline Clarification/Qualification & $\begin{array}{l}\text { I agree that they are largely safe but I don't know if all of } \\
\text { them are as effective as they state they are. (P71, Vaccines) }\end{array}$ \\
\hline Don't Know & I don't know anything about GMOs (P8, GMOs) \\
\hline None (explicitly stated) & N/A (P303, Evolution \& Climate Change) \\
\hline \multicolumn{2}{|l|}{ Subjective } \\
\hline Logical & $\begin{array}{l}\text { If they were not safe, they would not be put into the public } \\
\text { (P107, GMO) }\end{array}$ \\
\hline Moral & $\begin{array}{l}\text { I agree because we are causing this earth to suffer more than } \\
\text { what it has already suffer. Its up to us to change the problem } \\
\text { that we face in today society. (P183, Climate Change) }\end{array}$ \\
\hline Religious & $\begin{array}{l}\text { I am very strong on my religious views and do not believe in } \\
\text { biological evolution. (P53, Evolution) }\end{array}$ \\
\hline Cultural Identity & $\begin{array}{l}\text { I am very involved in nutrition and fitness lifestyles, and I } \\
\text { haven't heard of many cases of unsafe things happening to } \\
\text { people because of GMO foods. (P5, GMOs) }\end{array}$ \\
\hline Experience & $\begin{array}{l}\text { My only reason for agreeing with this statement is that my } \\
\text { whole family had childhood vaccinations and believe that it } \\
\text { has helped us all stay healthy. (P27, Vaccines) }\end{array}$ \\
\hline Belief-based / Circular & $\begin{array}{l}\text { Of course we affect our own environment. (P265, Climate } \\
\text { Change) }\end{array}$ \\
\hline Knowledge / Education & I dont really know anything about this topic. (P51, GMOs) \\
\hline Conspiracy ideation & $\begin{array}{l}\text { They have banned GMO's in many other countries and } \\
\text { America is completely ignorant to the horrible effects they } \\
\text { have because we are governed by a tiny group of people with } \\
\text { all of the money and power to make us blind and dumb. } \\
\text { (P135, GMOs) }\end{array}$ \\
\hline Controversy & $\begin{array}{l}\text { I honestly have no idea. I can see both sides of the argument } \\
\text { and cannot seem to make my mind up. (P135, Vaccines) }\end{array}$ \\
\hline Indifference / Don't care & $\begin{array}{l}\text { I have been exposed to many scientific and religious } \\
\text { explanations for how we have gotten to this point in life, and } \\
\text { quite frankly, it is very overwhelming and I do not care } \\
\text { enough to form a strong position for that topic. (P82, } \\
\text { Evolution) }\end{array}$ \\
\hline Natural & $\begin{array}{l}\text { modification means processing which will change nature } \\
\text { food charchteristic (P213, GMOs) }\end{array}$ \\
\hline Personal Choice & $\begin{array}{l}\text { I think that vaccines are important for the most part to keep } \\
\text { kids safe. I think that it is important that it is a choice with } \\
\text { certain vaccines because there are some vaccines that have } \\
\text { not been out long enough to have enough research done one } \\
\text { them and may not be necessary. (P148, Vaccines) }\end{array}$ \\
\hline
\end{tabular}




\begin{tabular}{cl}
\hline Evidential Justifications & $\begin{array}{l}\text { I agree with this statement because of the similarities that we } \\
\text { as humans have to other animals, as well as how many } \\
\text { animals are similar but because of where they live or come } \\
\text { from they have one distinct different feature that does puts } \\
\text { that at an advantage. (P149, Evolution) }\end{array}$ \\
\hline Mechanism & $\begin{array}{l}\text { Without evolution the species would not be able to adapt and } \\
\text { survive. they need to change and evolve as their environment } \\
\text { changes (P6, Evolution) }\end{array}$ \\
\hline Deferential & $\begin{array}{l}\text { Because scientists have said that this is a problem. (P101, } \\
\text { Climate change) }\end{array}$ \\
\hline Scientist / Science & $\begin{array}{l}\text { I am in an Environmental Health class and we learned about } \\
\text { GMOs, I believe we learned more positives than negatives } \\
\text { about GMOs. (P125, GMOs) }\end{array}$ \\
\hline Teacher / Class / Textbook & $\begin{array}{l}\text { News and everyone always encourages kids to get vaccines. } \\
\text { (P62, Vaccines) }\end{array}$ \\
\hline Other & \\
\hline Vague / Uncodable &
\end{tabular}

No Answer (empty response)

\section{Refutation Codes}

Denial

Subjective Refutations

Logical

Moral

\section{Prototypical Example}

My position will not change. (P18, Evolution)

(there were no responses coded with this code)

From all the things I have seen and read, it is far safer to have the vaccine and perhaps inconclusively suffer some ill effect than to allow thousands or perhaps more to die needlessly in an outbreak. We all did fine with all the vaccines when we were kids. (P207, Vaccines)

Religious Some sort of religious proof would be the only thing that would change my opinion. (P23, Evolution)

Cultural Identity Scientific resarch, by actual scientists. Not by political hacks or those paid by political hacks, to push an agenda (P281, Climate Change)

\begin{tabular}{ll}
\hline Experience & $\begin{array}{l}\text { If I or someone close to me has a negative experience with a } \\
\text { vaccine then I would be more concerned (P55, Vaccines) }\end{array}$ \\
\hline Belief-based / Circular & $\begin{array}{l}\text { Well obviously people eat GMO food everyday so I believe } \\
\text { it is okay to eat but I don't think it's the best option (P68, } \\
\text { GMOs) }\end{array}$ \\
\hline Knowledge / Education & Getting more information about the topic. (P24, GMOs) \\
\hline Conspiracy ideation & $\begin{array}{l}\text { I have to do more reading of the scientific literature. Again, } \\
\text { much of it is funded by the multinational corporations so } \\
\text { finding unbiased information isn't as easy as with other } \\
\text { topics. (P240, GMOs) }\end{array}$ \\
\hline
\end{tabular}




\begin{tabular}{|c|c|}
\hline Controversy & $\begin{array}{l}\text { Looking more into the topic and looking at both sides (P21, } \\
\text { Vaccines) }\end{array}$ \\
\hline Indifference / Don't care & $\begin{array}{l}\text { I would have to read about it, I have never even been } \\
\text { interested or concerned about it. (P47, GMOs) }\end{array}$ \\
\hline Natural & $\begin{array}{l}\text { That the earth is suppose to be going through this period of } \\
\text { climate change, like it happens every } 1 \text { million years or } \\
\text { something. (P57, Climate Change) }\end{array}$ \\
\hline Personal Choice & (there were no responses coded with this code) \\
\hline Counterfactual hindsight bias & $\begin{array}{l}\text { If people actually cared enough about the environment and } \\
\text { taking care of the earth, then there is a possibility of me } \\
\text { changing my position on this topic. (P58, Climate Change) }\end{array}$ \\
\hline Answering for others & $\begin{array}{l}\text { Someone who is religious could argue that God created } \\
\text { different species. (P175, Evolution) }\end{array}$ \\
\hline \multicolumn{2}{|l|}{ Evidential Refutations } \\
\hline Data/evidence & $\begin{array}{l}\text { If there is evidence that says otherwise, then I'll change my } \\
\text { position. (P144, Climate Change) }\end{array}$ \\
\hline Mechanism & $\begin{array}{l}\text { The introduction/propagation of a cohesive theory of the } \\
\text { development of organisms that is better supported than the } \\
\text { theory of evolution. (P267, Evolution) }\end{array}$ \\
\hline Unrealistic & $\begin{array}{l}\text { If I magically acquired a time machine \& I saw otherwise. } \\
\text { (P1, Evolution) }\end{array}$ \\
\hline Methodological & $\begin{array}{l}\text { If several sound studies using large numbers of participants } \\
\text { had same conclusions indicating questionable effectiveness } \\
\text { or safety I would possibly be swayed. (P257, Vaccines) }\end{array}$ \\
\hline \multicolumn{2}{|l|}{ Deferential Refutations } \\
\hline Scientist / Science & $\begin{array}{l}\text { If every scientist began saying there was a different reason } \\
\text { for the Earths temperature rise, then I would change my } \\
\text { mind. (P125, Climate Change) }\end{array}$ \\
\hline \multicolumn{2}{|l|}{ Teacher / Class / Textbook } \\
\hline Other & If they were not approved by the FDA. (P181, GMOs) \\
\hline Clarification / Qualification & $\begin{array}{l}\text { This is a topic I am in the middle on. I don't know what } \\
\text { proof/reason could be provided to provide evidence on either } \\
\text { side of this argument. (P256, Evolution) }\end{array}$ \\
\hline Don't $\mathrm{Kr}$ & I don't know. (P226, Climate Change) \\
\hline
\end{tabular}

No Answer (empty response) 